\title{
ESTUDIO ETNOARQUEOLÓGICO SOBRE LA CERÁMICA GZAUA (MARRUECOS). TÉCNICA Y CONTEXTO SOCIAL DE UN ARTESANADO ARCAICO
}

\author{
ETHNOARCHAEOLOGICAL STUDY OF GZAUA POTTERY (MOROCCO). TECHNIQUE AND \\ SOCIAL CONTEXT OF A TRADITIONAL CRAFTMANSHIP
}

JESÚS GONZÁLEZ URQUIJO $(*)$
JUAN JOSÉ IBÁNEZ ESTÉVEZ $(* *)$
LYDIA ZAPATA PEÑA $(* * *)$
LEONOR PEÑA CHOCARRO $(* * * *)$

\section{RESUMEN}

Las ceramistas de la tribu Gzaua (Chefchauen, Marruecos), dentro del contexto de producción de la cerámica beréber del norte del Magreb, emplean técnicas de fabricación mediante urdido, cocción en fuegos abiertos y distribución por trueque o venta en ámbitos geográficos restringidos. El estudio sobre las técnicas de fabricación y el contexto social de producción y uso de estas cerámicas ofrece una referencia relevante para la comprensión de las cerámicas de época prehistórica y sobre la cuestión de la especialización artesanal.

\begin{abstract}
The women pottery-makers in the Gzaua tribe (Chefchaouen, NW Morocco), who are part of the Berber pottery tradition of the north of the Mahgreb, still make ceramics with very archaic techniques. Pottery is constructed by slab building, open fired and exchanged in very restricted geographical area. The study of the techniques and of the social organization of production and use represents a rele-

(*) Dpto. de Ciencias Históricas. Universidad de Cantabria. Avda. de los Castros, s/n. 39005 Santander. Correo electrónico: jesuse.gonzalez@unican.es

(**) ERS 2091 Centre National de la Recherche Scientifique. IPO 07460 Jalès-Berrias. France. Correo electrónico: ibanezjj@ccaix3.unican.es

(***) Dept. of Archaeology. University of Cambridge. Downing Street. CB2 3DZ United Kingdom. Correo electrónico: 1z208@hermes.cam.ac.uk

(****) Laboratorio di Archeobiologia. Musei Civici di Como. Piazza delle Medaglie d'Oro 1.22100 Como. Italia. Correo electrónico: leonorpc@libero.it

El artículo fue remitido en su versión final el 5-I-2001.
\end{abstract}

vant reference for the specialists in pottery technology and, in general, for those interested in the topic of craft specialization.

Palabras clave: Etnoarqueología. Cerámica. Tecnología. Marruecos. Artesanía.

Key words: Ethnoarchaeology. Pottery. Technology. Morocco. Craftmanship.

\section{PLANTEAMIENTO Y OBJETIVOS}

Desde 1997 venimos desarrollando un proyecto de investigación etnoarqueológica en la zona occidental del Rif (1), en la Jebala marroquí (González Urquijo et alii, e.p.; Peña-Chocarro et alii, 2000; Ibáñez et alii, e.p. b). En este artículo presentaremos algunos de los resultados relacionados con la fabricación de las cerámicas.

El proyecto se diseñó para completar un marco de referencia que sirviera para la comprensión de las sociedades neolíticas en Europa y Próximo Oriente. La elección de las montañas rifeñas se debe a la suma de las condiciones ambientales, técnicas, económicas y sociales, apropiadas en algunos casos para servir de apoyo etnoarqueológico en las cuestiones prehistóricas planteadas: un medio montaño-

(1) Estos trabajos se han llevado a cabo dentro de los proyectos Las primeras sociedades campesinas. El aporte de la etnoarqueología en Marruecos financiado por la Fundación Marcelino Botín y Estudio de la tecnología tradicional en el Rif occidental, Proyecto de Cooperación Interuniversitaria Mohamed V (Rabat)/ Cantabria, subvencionado por la AECI. 
so en latitudes templadas, una economía con muy débil orientación hacia el mercado, con escasas diferencias sociales en el seno de las comunidades rurales y aspectos técnicos como la fabricación de cerámicas por urdido, el trabajo de piel con procedimientos manuales y curtientes naturales, el cultivo de cereales vestidos, la gestión de rebaños heteróclitos, la construcción de casas de adobe con cubiertas vegetales, etc...

El recurso a una observación etnoarqueológica directa deriva de nuestra convicción de que los modelos actualistas (Coudart, 1991; Fernández, 1994: 138), de forma implícita o explícita, suponen la base de nuestra comprensión del pasado. El actualismo puede tomarse como axioma -tal como se presenta en los manuales de geología- o de forma más matizada y pragmática, como hipótesis aceptada por la fecundidad interpretativa que representa su empleo (Gallay, 1995: 26).

La analogía, generalmente bajo la forma de inferencia inductiva ( $c f$. Gándara, 1990) es el instrumento que permite interpretar los comportamientos pasados a la luz de la observación de los presentes. La cuestión se centra en establecer cuándo la analogía es pertinente. Esto requiere aceptar que los dos términos que entran en la comparación tienen propiedades equivalentes en algún grado, es decir, que son comparables. Partimos aquí de un presupuesto más moderno que posmoderno sobre las regularidades en el comportamiento de los grupos humanos.

No se nos oculta que en el caso de las sociedades humanas la pertinencia de la comparación depende además de nuestra concepción sobre el funcionamiento de los procesos históricos. En las versiones idealistas se pedirá que haya una continuidad histórica o cultural (2) (cf. Hole, 1978; Criado, 1993: 18 para el paisaje gallego, o la obra general de J.M. de Barandiarán, 1979 y 19721983). En las materialistas se atenderá más a la comunidad de condiciones ambientales y económicas, o-para los marxistas- a la semejanza estructural en el estadio de desarrollo socioeconómico (Gándara, 1990; Forest, 1992). Es evidente que la confianza aumenta cuanto mayores son las semejanzas estructurales entre las sociedades comparadas, pero no es esperable encontrar referentes 'perfectos' para la mayor parte de las sociedades prehistóricas. Ante esta constatación, en nuestro

(2) Se trataría de homologías más que de analogías, en el sentido que se encuentra por ejemplo en M. Porr (1999). caso hemos primado la consideración de los aspectos económicos y sociales a la hora de seleccionar un marco pertinente.

Además de pertinente, la analogía debe ser válida. La etnoarqueología ha padecido los abusos de la generación de analogías formales, 'ad hoc', basadas en parecidos superficiales entre dos fenómenos. Estas comparaciones simplistas inducen a menudo al error. Es preciso establecer que las relaciones son relevantes, es decir, fundadas en la estructuración causal de los fenómenos comparados (Wylie, 1985: 104; 1988: 146; Fernández, 1994: 163; Hernando, 1995: 20). La comparación es más sólida y útil cuanto más amplios sean los fenómenos comparados y más abundantes los referentes independientes que se aporten.

El ámbito de aplicación de los enfoques etnoarqueológicos es objeto de debate regular. $\mathrm{Al}$ abordar problemáticas sobre tecnología prehistórica, sobre adaptaciones ecológicas o sobre prácticas económicas, la etnoarqueología puede suponer una suerte de experimentación en vivo (Beyries, 1997, 1999; Rodríguez, 1999). En este caso las restricciones en la gama de comportamientos posibles, que impone la naturaleza de los materiales físicos, y la posibilidad de desplegar una panoplia de análisis a partir de los restos materiales generados asegura la pertinencia de la analogía, para la que existen en último término referentes empíricos más fáciles de contrastar. Sin embargo, cuando pretendemos reconocer comportamientos de índole social o ideológica, la epistemología es más compleja y arriesgada (Stozckowski, 1992) o sencillamente inabordable (Petrequin y Petrequin, 1992), aunque para otros es precisamente el campo de aplicación más apropiado (Hernando, 1995, 1997).

La segunda fase de un enfoque etnoarqueológico es la interpretación de un problema histórico. Aquí se despliegan de nuevo las condiciones que avanzábamos para aceptar la validez de la analogía. La interpretación debe dirigirse a las causas más que a las formas y debe estructurarse en forma de modelos de relaciones entre los distintos aspectos examinados. El proceso hermenéutico se facilita si disponemos de un conocimiento exhaustivo del registro etnográfico, de forma que se puedan establecer diversas líneas de explicación alternativas; este mismo proceso es más sólido si la contrastación de las hipótesis que sustentan la explicación es amplia, basada en aspectos diversos e independientes del registro arqueológico (Keeley, 1992; Ibáñez et alii, e.p. a).

T. P., 58, n. ${ }^{\circ} 1,2001$ 
Además de generar analogías pertinentes, una aproximación etnoarqueológica proporciona también elementos para desarrollar un marco conceptual general, inevitablemente más difuso e intuitivo (sensu Tilley, 1994). El marco conceptual permite superar la casuística de los ejemplos etnográficos concretos, dando respuesta a uno de las principales carencias potenciales de las analogías actualistas en la interpretación histórica, como es el riesgo de no encontrar nunca nada nuevo, limitados a explicar el pasado a partir de los ejemplos necesariamente parciales que conocemos en el presente.

En este artículo nos vamos a centrar en las características del proceso técnico de elaboración de las cerámicas y en el contexto económico y social de la producción con dos objetivos primordiales. En primer lugar, relacionar los comportamientos técnicos con los restos materiales que generan, aportando referencias que permitan la interpretación de los restos arqueológicos. En segundo lugar, analizar las características de un proceso productivo artesanal -es decir, practicado por especialistas y destinado al intercambio- y las diferencias que presenta respecto a las producciones domésticas. En este artículo no aplicaremos los datos etnográficos a ningún contexto arqueológico concreto, sino que, en un sentido más amplio, pretendemos ofrecer elementos que coadyuven a mejorar el marco teórico con el que abordar el estudio de la cerámica y, en general, de la especialización artesanal en la Prehistoria.

Las informaciones que presentamos proceden del trabajo de campo desarrollado entre los años 1997 y 2000, en una estancia total de alrededor de cinco meses y medio. Hemos realizado una observación directa -en ocasiones participante- entre las mujeres que aún mantienen la técnica. Para obtener informaciones sobre estos aspectos en el pasado, en los últimos 60 años, nos hemos basado en encuestas a las ceramistas ancianas o a aquellos que usaron las cerámicas.

\section{LA CERÁMICA GZAUA}

La región Jebala se encuentra en el Rif occidental, en el NO. de Marruecos (Fig. 1). La tribu Gzaua se sitúa al sur de Chefchauen, ya en la vertiente meridional -atlántica-de las montañas rifeñas, en el valle alto del río Lucus, alrededor del pequeño núcleo poblacional y mercado de Mokrisset. La tribu ocupa una región de relieve accidentado, mode-

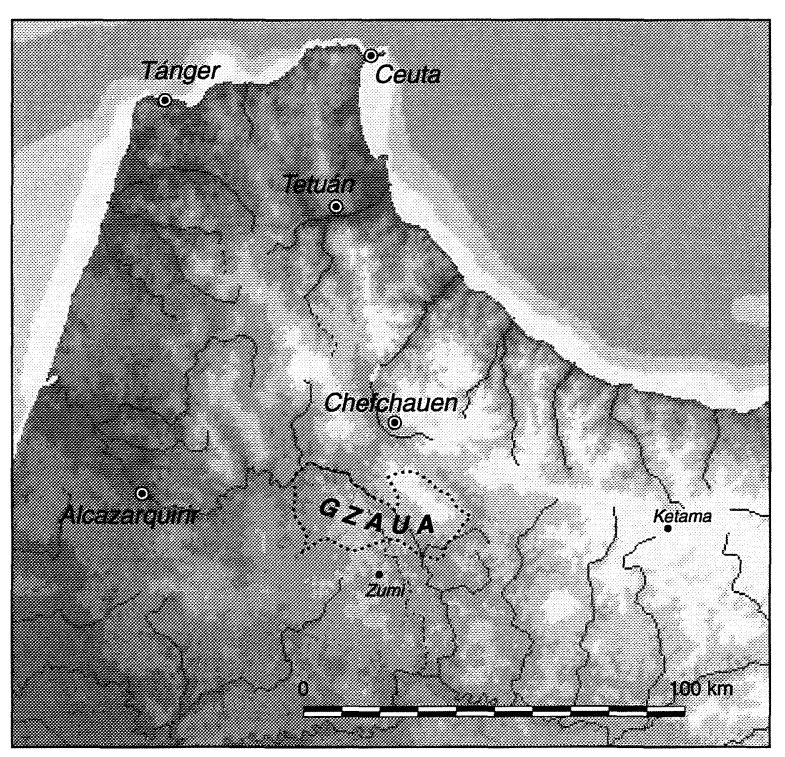

Fig. 1. Mapa del norte de Marruecos. Localización de la tribu Gzaua en el Rif occidental.

lado a partir de la orogenia alpina; la mayor parte de las aldeas se sitúan en zonas de ladera, en altitudes entre los 200 y los $600 \mathrm{~m}$ de altitud. El clima es mediterráneo de influencia atlántica, con precipitaciones relativamente abundantes, por encima de $1000 \mathrm{~mm}$ anuales (Chikhi y ElAbdellaoui, 1996).

La producción de cerámica en esta tribu, realizada por mujeres mediante urdido, se entronca dentro de la tradición de la cerámica beréber, extendida a lo largo de las zonas montañosas septentrionales de Marruecos, Argelia y Túnez (Balfet, 1965; Camps, 1987; Fayolle, 1992; Picon, 1993; Vossen y Ebert, 1986; Vossen, 1990).

Entre las ceramistas Gzaua existían diversos esquemas de producción y distribución de las cerámicas. El más sencillo consiste en mujeres que producen cerámica exclusivamente para uso propio o para regalar a alguna vecina o familiar. En segundo lugar, aquellas mujeres que fabrican para la venta en el propio duar (aldea). Por último, las artesanas que destinan su producción a la venta en el zoco. Los dos primeros esquemas de producción han desaparecido en los últimos años.

Hemos conocido sólo un caso de una ceramista que en el pasado producía recipientes exclusivamente para uso propio, en la aldea de Dar el Ued. Esta mujer ayudaba a una ceramista que vendía en el zoco, preparando la arcilla, pintando y cociendo a cambio de un pago en dinero. Se trata de una mujer pobre que fabricaba además su propia cerá- 
mica doméstica. La producción de cerámicas para la venta o trueque en el propio duar fue un esquema más extendido, habiendo conocido casos en Agbalu, Hommar y Miknanu. En estos dos esquemas productivos se elaboraban cerámicas culinarias no pintadas, destinadas a la preparación de los alimentos y al cocinado. Se trata en todos los casos de recipientes de formas abiertas -variantes de platos y cuencos.

Sin embargo, el esquema productivo más generalizado ha sido el orientado a la distribución en el zoco. Dentro de este esquema se realizan dos tipos de cerámicas, una decorada con pintura, que se usa para contener líquidos (agua, aceite y leche) y otra culinaria, sin pintar. En la actualidad aún quedan mujeres ceramistas en activo en Ain Kob, Dahar y Briet. Sin embargo, en el pasado, el número de duares donde se fabricaba cerámica era mucho mayor (3). En algunos de ellos se fabricaba la cerámica culinaria y la pintada, mientras que en otros sólo elaboraban la culinaria. Esta dedicación ha podido cambiar a lo largo del tiempo. Así, en Agbalu hasta hace unos 50 años se hacían tanto cerámica pintada como culinaria, pero a partir de esa época se abandonó la fabricación de la pintada. La factura de la cerámica pintada es más compleja, ya que se realizan cántaros de hasta $60 \mathrm{~cm}$ de altura con cuello, y requiere de algunas materias primas específicas o exóticas -las arcillas y los colorantes, respectivamente.

La producción cerámica ha sufrido un claro retroceso en los últimos veinte años. La escasa cerámica pintada que se elabora en la actualidad se destina en buena parte a la venta a los turistas. La cerámica culinaria apenas se produce, $\mathrm{y}$, cuando se fabrica, sirve para el autoconsumo o para satisfacer encargos de algún vecino o familiar. Esta decadencia no ha influido demasiado en las técnicas empleadas, que siguen siendo las mismas que en el pasado, pero sí ha modificado aspectos referidos a la intensidad de la producción, sistemas de comercialización y uso de los recipientes.

A continuación nos referiremos, en primer lugar, a los aspectos técnicos de la fabricación en los tres esquemas productivos, siguiendo la ordenación cronológica del proceso técnico, para discutir más tarde algunos aspectos del contexto económico y social.

(3) Ain Kob, Briet, Dahar, Kalaa Harrakin, Saara, Dar Haidor, Dar el Ued, Agbalu, Uled Skira y Tazult; es decir, 10 de entre las aproximadamente 20 aldeas de la fracción (arba) Bani Chaib donde se concentran la mayor parte de las artesanas.

\section{LA PRODUCCIÓN CERÁMICA}

\section{Pozos y minas: la obtención de las materias primas}

En la cerámica Gzaua se emplean varios tipos de arcillas y desgrasantes, mezclados o no en proporciones variables según los lugares, el destino de la producción o el tipo de recipientes fabricados. Por su parte, los colorantes son exclusivamente minerales y proceden en algunos casos de afloramientos muy alejados.

En los ejemplos que hemos conocido de fabricación de cerámicas para uso propio o para intercambio en el duar, se emplea un solo tipo de arcilla de color rojo, usando como desgrasante pequeñas piedras milimétricas de margas o calizas pizarrosas (asegan). La arcilla se obtiene en las cercanías del pueblo, a veces en el mismo huerto de la casa, cavando pequeños agujeros por parte de la propia ceramista. El desgrasante es producto del cribado con cedazos de las gravas naturales que aparecen en la región.

Para la cerámica destinada a la venta en el zoco, la obtención de la materia prima es más compleja. Las cerámicas para uso culinario se fabrican utilizando dos tipos de arcillas, una roja y una blanca, mezcladas con el desgrasante mineral. Las cerámicas para contener líquidos, normalmente pintadas, se elaboran con la arcilla blanca y desgrasante. $\mathrm{La}$ arcilla roja es común en toda la región, mientras que la blanca es más escasa, sólo se encuentra en algunas aldeas.

En la actualidad, las arcillas roja y blanca se explotan en pequeños agujeros abiertos en las laderas (Lám. I). El acceso a la materia prima es libre, sin mediar pago alguno. La arcilla es recogida in-

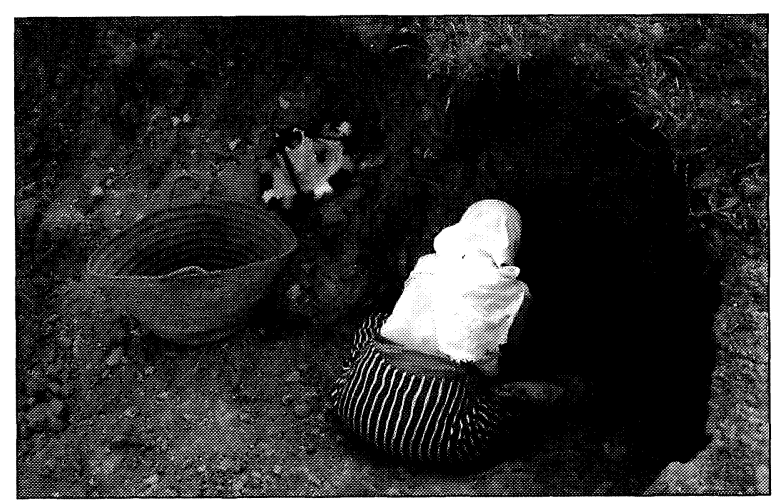

Lám. I. Pozos para la extracción de la arcilla blanca en Ain Kob (Rif occidental).

T. P., 58, n. $^{\circ} 1,2001$ 
dividualmente por las propias ceramistas. Este sistema de recogida de la materia prima fue común en el pasado, salvo por el hecho de que en algunos lugares se practicaban pequeñas minas para extraer la arcilla blanca.

Estas minas de arcilla blanca se encontraban en Ain Kob y Dar el Ued. La última mina abierta en Ain Kob consistía en una galería-pozo. El pozo de entrada alcanzaba hasta 3,5 m. de profundidad, con un paso de $2 \mathrm{~m}$ de alto por $1 \mathrm{~m}$ de ancho; contaba con escalones tallados para facilitar la entrada y la salida de las trabajadoras. A partir del pozo se abría una galería amplia, a la que se accedía a través de un estrechamiento a modo de puerta. La galería podía tener $2 \mathrm{~m}$ de ancho, 8 ó $10 \mathrm{~m}$ de largo y 1,80 $\mathrm{m}$ de alto, de forma que las mujeres entraban de pie. Estas minas nunca se entibaban. No utilizaban iluminación artificial; trabajaban con la luz exterior, una vez que se habían acostumbrado a la penumbra. Se abrían agujeros en las paredes o en el suelo de la galería, donde se realizaba la explotación individual. Algunos de estos agujeros podían tener hasta $2 \mathrm{~m}$ de longitud, y en ellos se entraba gateando.

Las minas se excavaban al principio del verano, dado que es en esta estación cuando las labores de fabricación de la cerámica son más intensas. Casi todos los años debían abrir una nueva explotación debido a que las minas abiertas solían hundirse en el invierno a causa de las lluvias. Durante el invierno, cuando la necesidad de arcilla es escasa, la tomaban de pequeños pozos.

Cuando iban a comenzar la explotación de una nueva mina, varias mujeres se ponían de acuerdo y trabajaban en equipo. Todas ellas iban rotando en los trabajos de picar, cargar o retirar la tierra a medida que hacía mella el cansancio. La preparación de la mina requería de 20 a 30 días de trabajo, dedicando varias horas al día. La morfología de la mina era fruto de la experiencia de las mujeres, sin que hubiera un plan explícito.

Una vez acabado el trabajo de preparación de la mina, la explotación pasaba de ser colectiva a ser individual. En la práctica, siempre trabajaban al menos dos mujeres, una para picar y otra para sacar la tierra. Una vez que la mujer que picaba ya se había aprovisionado, la que sacaba la tierra pasaba a tomar su lugar. En la mina no había un lugar específico de explotación de cada ceramista. Si una ceramista estaba explotando una buena veta, otra podía continuar en el mismo punto. El trabajo en las minas era peligroso, pues, al no estar entibadas, existía un continuo riesgo de desplomes que se ma- terializaron en algunas ocasiones, en ambas minas. De hecho, las mujeres que quedaban en el exterior para sacar la arcilla también vigilaban por si el techo mostraba indicios de hundimiento.

La apertura de minas se abandonó cuando declinó la producción cerámica y la explotación de la arcilla blanca se redujo a la apertura de pequeños pozos. La última mina fue abandonada hace cerca de 20 años.

Hemos visitado los lugares donde existieron las minas de Ain Kob y hemos comprobado su escasa visibilidad arqueológica. Apenas una ligera hondonada en el terreno indica la antigua presencia de la mina. Los pequeños pozos que genera la extracción de la arcilla roja son aún más difíciles de detectar.

En estas minas, además de las mujeres del propioduar, también se aprovisionaban ceramistas de las aldeas vecinas. A la mina de Dar el Ued acudían mujeres de Tazult (a $2 \mathrm{~km}$ ) y de Dar Haidor (a 3 $\mathrm{km}$ ), mientras que la mina deAin Kob era frecuentada por mujeres de Kalaa Harrakin (a 2 km). Las ceramistas de Saara, algunas de ellas con parientes cercanos en Ain Kob, acudían a ambas minas.

Para la decoración de las cerámicas pintadas se emplean colorantes minerales: el blanco (mlala), con el que se engoban los recipientes, el rojo y el negro, con los que se realizan los trazos decorativos. El colorante rojo es muy abundante, y se recoge en las cercanías de las aldeas. Sin embargo, el colorante negro y el blanco proceden de lugares más alejados, a los que hay que llegar tras varias horas de marcha. A veces, los colorantes procedentes de estas zonas más alejadas se obtenían por intercambio y todas las ceramistas de la zona empleaban los mismos colorantes. La tendencia a que la arcilla para la fabricación cerámica se recoja cerca del lugar de producción, mientras los colorantes se adquieren en lugares alejados ya ha sido señalada para otros contextos etnográficos (Rice, 1987: 117-118).

\section{Mezclas y cribas: la preparación de la pasta}

$\mathrm{La}$ arcilla blanca requiere un tratamiento previo ya que cuando es de buena calidad queda compacta, en terrones, que deben ser molidos; cuando la arcilla es de mala calidad resulta pulverulenta en el momento de la extracción. Para el molido, dejan secar la arcilla y después la golpean con un mazo dentado (Lám. II). Este mazo (rzama) es el útil tradicional empleado en la región para descascarillar 


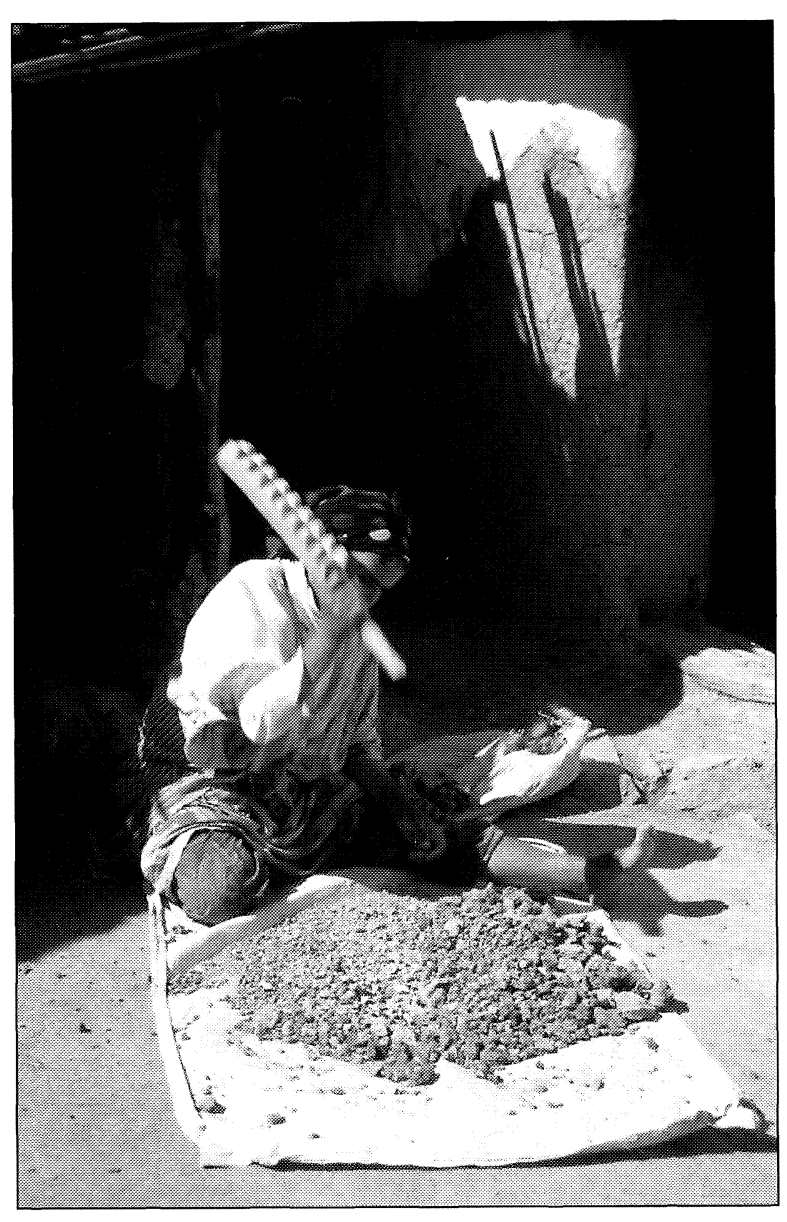

Lám. II. Molido de la mezcla de arcillas con ayuda del rza$m a$, en Briet (Rif occidental).

el skalia (Triticum monococcum) o para desgranar las leguminosas. El molido se realiza en el patio de la casa, aunque cuando llueve pueden trabajar en un lugar cubierto; el molido se hace directamente sobre el suelo y este debe estar seco. Si se van a emplear varias arcillas en la fabricación se mezclan previamente y son molidas al mismo tiempo. Cuando la arcilla está parcialmente molida, la artesana la criba con un cedazo. La fracción fina se reserva y se continúa moliendo el resto de la arcilla. Después se añade y se mezcla el desgrasante.

Para comenzar la fabricación, la ceramista amontona una cierta cantidad y abre una pequeña depresión en el centro, donde vierte el agua. Después amasa la arcilla con las manos y prepara varias pellas en forma de rollo. Estos rollos son envueltos en plástico y guardados en el exterior, junto al muro de la casa, pudiendo almacenar la arcilla así preparada hasta 5 meses. Los rollos se guardaban envuel- tos en tejidos o pieles antes de la introducción del plástico.

Existe otra forma de preparación de la pasta. Una vez que la arcilla ha sido machacada con el rzama se introduce en agua y queda en remojo al menos 24 horas, hasta que al día siguiente se mezcla con el desgrasante y se amasa. Existe un riesgo al tomar esta alternativa ya que, al no estar la arcilla cribada, pueden quedar fragmentos compactos de calibre demasiado grande, que estallan durante la cocción y rompen la cerámica. Por ello, mientras la ceramista amasa la pasta al día siguiente va eliminando las intrusiones que reconoce al tacto. Esta circunstancia prolonga extraordinariamente la fase de amasado. Hemos encontrado esta técnica entre ceramistas que producen cantidades de cerámica relativamente pequeñas.

El sistema de preparación de la arcilla por cribado está asociado a la producción de las cerámicas que se distribuyen en el zoco. El sistema de inmersión de la arcilla en agua se asocia a la producción de cerámica para venta en el propio duar aunque en algunos casos también se preparan de este modo cerámicas culinarias que se destinan al zoco.

La elaboración de los distintos tipos de cerámica se lleva a cabo a partir de diferentes mezclas de arcillas. La arcilla blanca se emplea para fabricar los recipientes contenedores de líquidos porque ofrece plasticidad, permite la fabricación de formas cerradas con cuello, favorece el buen acabado de las superficies de los vasos para recibir la decoración pintada y, en opinión de los usuarios, mantiene los líquidos frescos porque permite una ligera transpiración. La arcilla roja se emplea para las cerámicas culinarias porque aumenta la tenacidad de los cuencos ante los esfuerzos mecánicos propios del amasado del pan o la elaboración del cuscús y permite que soporten el impacto térmico en aquellas que entran en contacto con el fuego. Como ya hemos señalado las ceramistas que elaboran cerámicas culinarias para uso propio o intercambio en elduar, sin venta en el zoco, sólo utilizan la arcilla roja, mientras que las cerámicas culinarias de las mujeres que venden en el zoco mezclan la arcilla roja con la blanca.

Dentro del esquema general señalado para la cerámica que se vende en el zoco, en cada duar puede haber variabilidad en las proporciones en que se mezclan los diversos componentes. EnAin Kob la cerámica pintada, destinada a contener líquidos, se elabora con arcilla blanca (2/3) y desgrasante (1/ $3)$. La cerámica culinaria necesita una mezcla dife- 
rente: arcilla blanca (1/2), arcilla roja (1/4) y desgrasante calizo (1/4). En Briet, la cerámica culinaria es elaborada con $1 / 3$ de arcilla blanca, $1 / 3$ de arcilla roja y $1 / 3$ de desgrasante.

También hemos observado que en distintas partes de un mismo recipiente se pueden emplear mezclas diferentes de arcillas. En Saara se fabrican recipientes grandes, de hasta 100 litros de capacidad, donde se introducen las pieles para el curtido (Lám. III). Para la preparación de la pasta se sigue el mismo sistema que el señalado para la cerámica culinaria en Briet, con tres partes iguales, de las dos arcillas y los desgrasantes. Pero añaden también una arcilla con desgrasantes que se prepara aparte, porque necesita más agua durante el amasado. Esta nueva arcilla se mezcla con la pasta anterior, amasando de nuevo para obtener una mezcla homogénea. La finalidad de añadir esta arcilla plástica es la de mejorar la impermeabilidad a los recipientes, que deben contener el líquido curtiente durante varias semanas. Sin embargo, en las zonas del recipiente que no tienen que cumplir esta función, como las asas o el verdugón decorativo, los rollos se preparan sin añadir esta arcilla plástica.

En la cerámica Gzaua existe una vinculación clara entre la composición de las pastas de las cerámicas y las funciones que ésta cumple, con al menos tres variantes: contenedores de líquidos, cerámicas culinarias - para el procesado o la cocción- y barreños de curtido de piel. El caso de estos últimos resulta revelador ya que las pastas empleadas en las distintas partes del recipiente dependen estrictamente de la función que cumplen: las paredes y el fondo con arcillas impermeabilizantes; las partes decorativas o de prensión, sin ellas. La preparación cuidadosa de las arcillas mediante molido y cribado puede reconocerse en el análisis de las pastas de los propios recipientes y probablemente en los análisis micromorfológicos del sedimento en las áreas de actividad.

\section{El modelado de los recipientes}

El trabajo se desarrolla principalmente en verano, puesto que en época de lluvias la arcilla tarda mucho en secar y es difícil trabajarla. En invierno, aprovechando los periodos sin lluvias, sólo fabrican los quemadores de carbón (mishmar) o los platos para cocer el pan (makla) pues son los tipos de vasos más demandados en esta época del año.

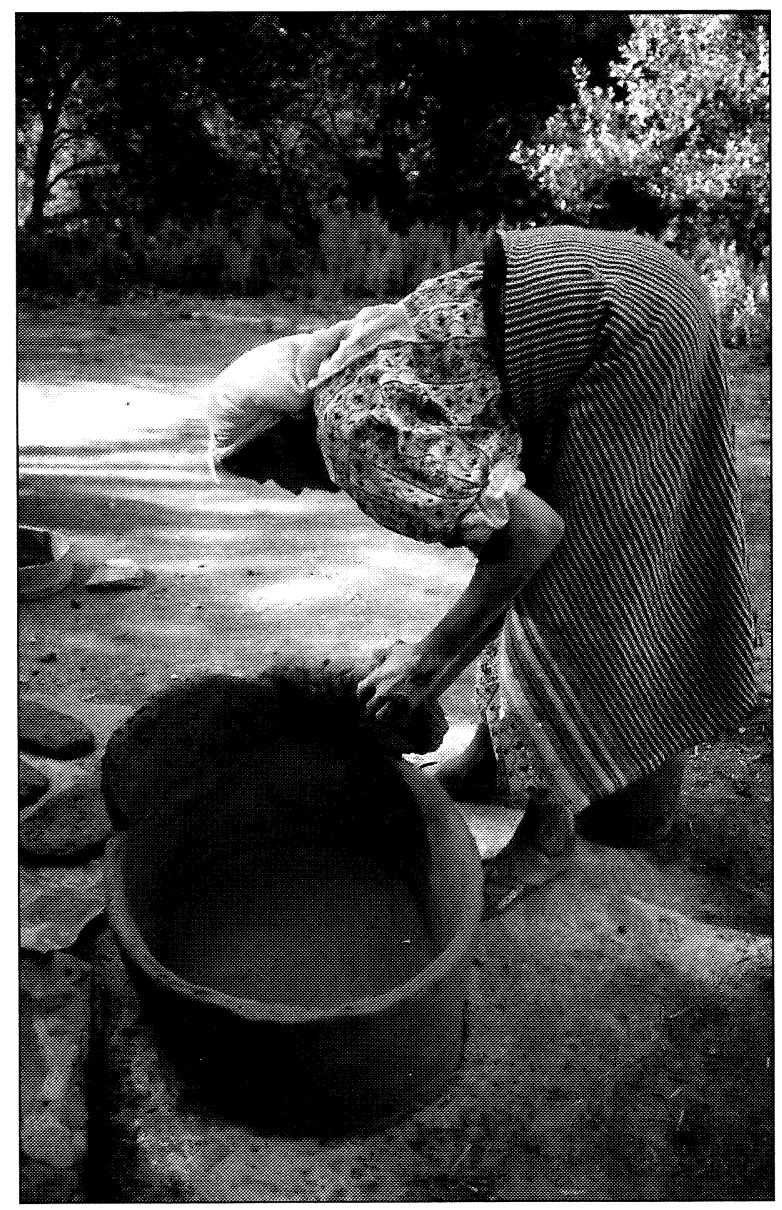

Lám. III. Preparación de los grandes cuencos de cerámica para el curtido de la piel, en el duar de Saara (Rif occidental).

La cerámica se elabora en el ámbito doméstico, generalmente en el patio exterior, aunque no existe un lugar de trabajo fijo. Durante el proceso de elaboración, a veces, la ceramista cambia de lugar, buscando la sombra o cualquier otra condición de comodidad. Trabajan sentadas en el suelo, generalmente con la pierna izquierda extendida y la derecha recogida (véase la Lám. II y las siguientes). La postura resulta incómoda y dolorosa después de varias horas de trabajo.

Se emplea una técnica de urdido (Lám. IV A). Los recipientes se elaboran sobre bases hechas con lajas planas de piedra, planchas de madera, tortas fabricadas con arcilla mezclada con estiércol de vaca, secadas al sol, o sobre los fondos de recipien- " tes de cerámica rotos. Las artesanas colocan sobre estas bases una torta plana y circular de arcilla que corresponderá al fondo del vaso. Después preparan 

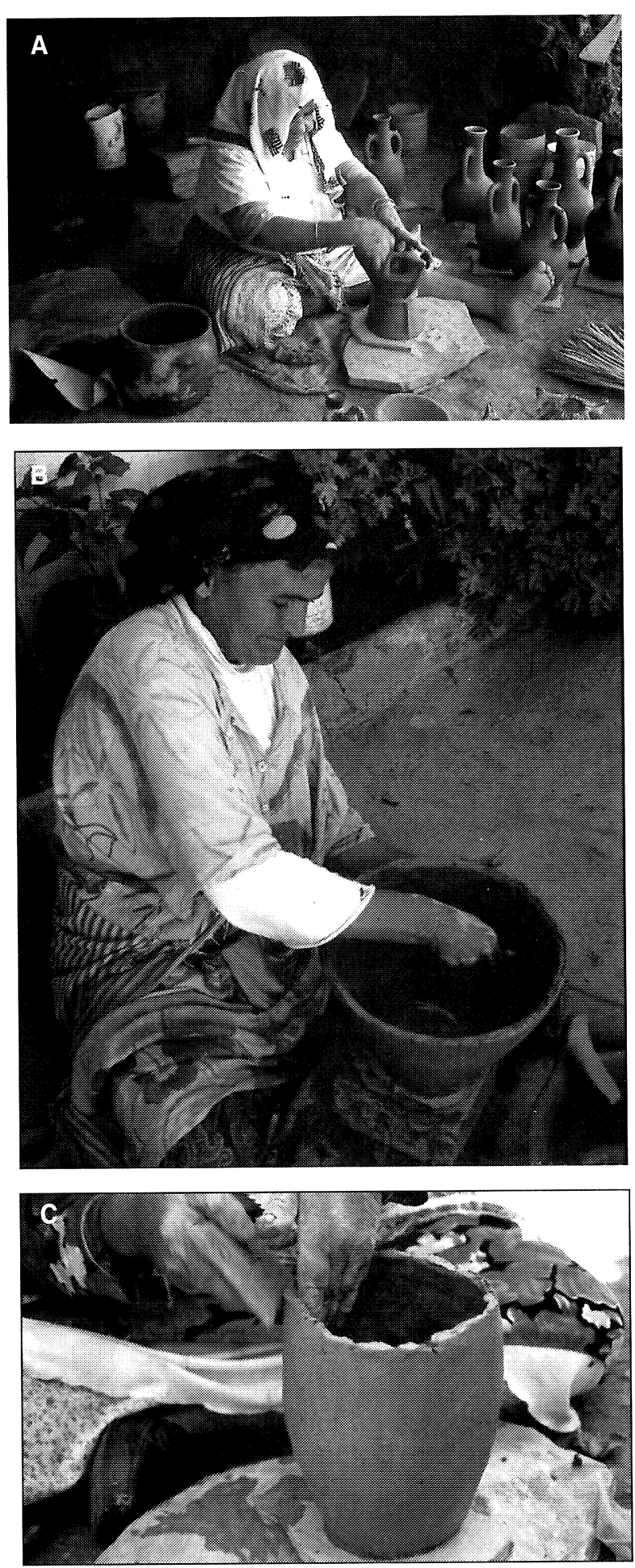

Lám. IV. Modelado de la cerámica por la señora Fton, en Ain Kob (A); regularización de las paredes interiores del cuenco con una espátula de madera, en Briet (B) y de las paredes exteriores por el mismo sistema, en Ain Kob (C)(Rif occidental). un rollo de arcilla que colocan como un anillo ajustándolo alrededor del perímetro de la base; a partir de este primer rollo levantan las paredes unos 10$15 \mathrm{~cm}$. Para ello presionan la arcilla con las palmas de las manos y luego regularizan las paredes con espátulas de madera (Lám. IV B, C). Estas espátulas son en origen rectangulares, pero, por el uso, los lados largos quedan cóncavos y muestran un filo en bisel. Disponen al menos de media docena de espátulas de diferentes tamaños, que se usan en función de las dimensiones de la cerámica a elaborar. Para elevar más las paredes del recipiente, adosan un nuevo rollo sobre la parte ya elevada, después de un tiempo de secado, y repiten la operación. La elaboración de los modelos más grandes, de hasta $50 \mathrm{~cm}$ de altura, requiere hasta cuatro rollos con sus fases de secado intermedias. Las asas y los cuellos son los últimos elementos que se aplican. El labio se regulariza con pequeños golpes aplicados con la cara plana de una espátula de madera.

Después de esta primera fase de elaboración las cerámicas se dejan secar a la sombra, para que vayan perdiendo la humedad poco a poco; al sol se fisuran. Cuando las cerámicas están más consistentes se añaden los apliques necesarios, verdugones en los cuencos para el pan y cuscús, tres pestañas en los braseros para apoyar las cazuelas y asas para las cerámicas de agua. Si el secado ha sido demasiado prolongado los apliques de arcilla sobre la cerámica no se fijan, por lo que el tiempo de secado debe ser controlado. En invierno el secado se puede acelerar colocando los recipientes en el horno de pan o alrededor de pequeñas hogueras en las habitaciones de la casa.

El acabado de las cerámicas se realiza con un trozo de cuero o con un canto de piedra humedecidos, frotando la superficie a medio secar, para conseguir un ligero bruñido. El frotado con cantos también se puede practicar después de la cocción. Las ceramistas ofrecen una explicación estética para esta labor, aunque hemos observado que el bruñido tiene a veces un sentido funcional. Así, en Dahar, en los recipientes para preparar el cuscús solo se bruñe el interior, para que resbalen bien los granos de sémola, mientras en las cazuelas donde se consume la comida se bruñe tanto el interior como el exterior. En otros recipientes, como los braseros o los grandes contenedores para aceite, no se suelen acabar las paredes de este modo.

Las ceramistas también utilizan cuchillos de metal en diferentes fases del trabajo. Las paredes de arcilla fresca de los recipientes pueden ser cortadas 
para conseguir la forma adecuada. Estos útiles también sirven para raspar las rebabas que quedan en las bases de las cerámicas cuando, una vez secas, se separan de las placas sobre las que se han apoyado durante el modelado.

Hay diversos grados de dificultad en la elaboración de la cerámica. Los platos y los cuencos abiertos presentan una dificultad escasa, mientras que las formas cerradas de sección fusiforme son más complejas. En el modelado de los cántaros de gran tamaño, el punto crítico es la elevación del cuello, cuyo peso puede desplomar el recipiente durante la elaboración o durante el secado posterior; ésta es la razón por la que se aprecian las cualidades de la arcilla blanca en estas piezas y se ciñe la temporada de fabricación al verano, para permitir un secado más rápido.

La técnica tiene lugar en el ámbito doméstico, sin que existan estructuras constructivas destinadas a taller o almacén. Los útiles y el escaso material o producción almacenada pueden estar guardados en cualquier habitación. Muchos de los útiles están realizados en materiales perecederos, como los rzama (mazos), las espátulas de madera o los paños de cuero. Otros útiles son recuperables en yacimientos arqueológicos, como los cantos rodados, usados para la regularización y bruñido de los recipientes, o como los útiles cortantes, cuchillos de metal en este caso, pero útiles de sílex en el pasado prehistórico, usados para cortar partes de los cuencos con el barro fresco o para raspar las rebabas de la base, con el barro seco. Dentro de esta categoría se encontrarían la mano y el metate para moler los colorantes. Estos útiles son usados durante décadas, incluso generaciones, por lo que un análisis de huellas de uso o de residuos podría detectar su función (Gassin, 1996; Ibáñez y Zapata, e.p.). Algunas de las artesanas se quejaban de fuertes dolores, situados en las articulaciones, sobre todo en la cintura; no sería extraño encontrar evidencias de la hipersolicitación muscular que se hace durante el trabajo a partir de análisis osteológicos (4).

\section{La decoración}

La cerámica culinaria destinada al autoconsumo o venta en el duar no se decora. En ocasiones se decora la cerámica de cocina destinada al zoco. Por

(4) Tenemos noticia de dos ceramistas al menos que no podían andar debido a problemas en la cintura aunque no hemos podido confirmar la relación con las actividades artesanales. ejemplo, en Ain Kob se añaden verdugones alrededor del tercio superior del galbo, que suelen estar decorados con incisiones verticales paralelas, realizadas con los bordes de las espátulas de madera.

A diferencia de la cerámica culinaria, la cerámica para contener líquidos se pinta. Los vasos se engoban en blanco en su parte exterior y en la zona interior cercana al labio, aplicando el colorante con un paño o con un manojo de lana de oveja. Sobre esta base se pinta con colores rojo y negro. Todos los colorantes son de origen mineral y se denominan genéricamente al-mogra.

Los minerales usados como colorantes se muelen. Debido a la diferente dureza de cada uno de ellos el proceso de molido es ligeramente diferente. El colorante rojo, más blando, se aplasta dentro de un pequeño cuenco de cerámica. El negro es machacado y molido mezclado con agua con un canto sobre una laja de piedra cóncava. Algunos de los cantos han sido usados durante generaciones y muestran unós desgastes muy acusados.

Los pinceles se impregnan en la laja o en la cerámica que sirve para el molido de los pigmentos. Cuando la pintura se espesa por la evaporación, añaden un poco más de agua y vuelven a mezclar, en su caso ejerciendo un movimiento circular con el canto. Elaboran los pinceles cortos con fibras vegetales o con pelo de cabra. Para ello, unen las fibras con una pella de arcilla de forma cilíndrica, que dejan secar. Las fibras o pelos sobresalen del cilindro por ambos extremos, con lo que disponen de dos pinceles por pieza; arreglan las cerdas de modo que uno permite trazar líneas gruesas y el otro más finas. Usan pinceles distintos para cada colorante.

Las decoraciones mezclan los trazos rojos y negros, delineando formas geométricas, como rombos, tramas de líneas, alineaciones de trazos paralelos, etc. El labio de las cerámicas se cubre con una banda de pintura negra, que se aplica con un paño impregnado en pintura. Esta misma técnica es la que se usa para decorar con puntuaciones negras en el exterior de las asas. La decoración con trazos suele comenzar delineando la zona alta de la panza con trazos horizontales. Después se segmenta el vaso con líneas verticales, desde el labio hasta la mitad de la panza, llenando con líneas oblicuas y entramados cada uno de los cuarteles (Lám.V A).

En la actualidad se puede encontrar decoración pintada sobre muy diversos tipos de recipientes, pero en el pasado la pintura se destinaba fundamentalmente a cuatro tipos: asakai, cántaros con asas y cuello estrecho, usados para traer el agua desde la 

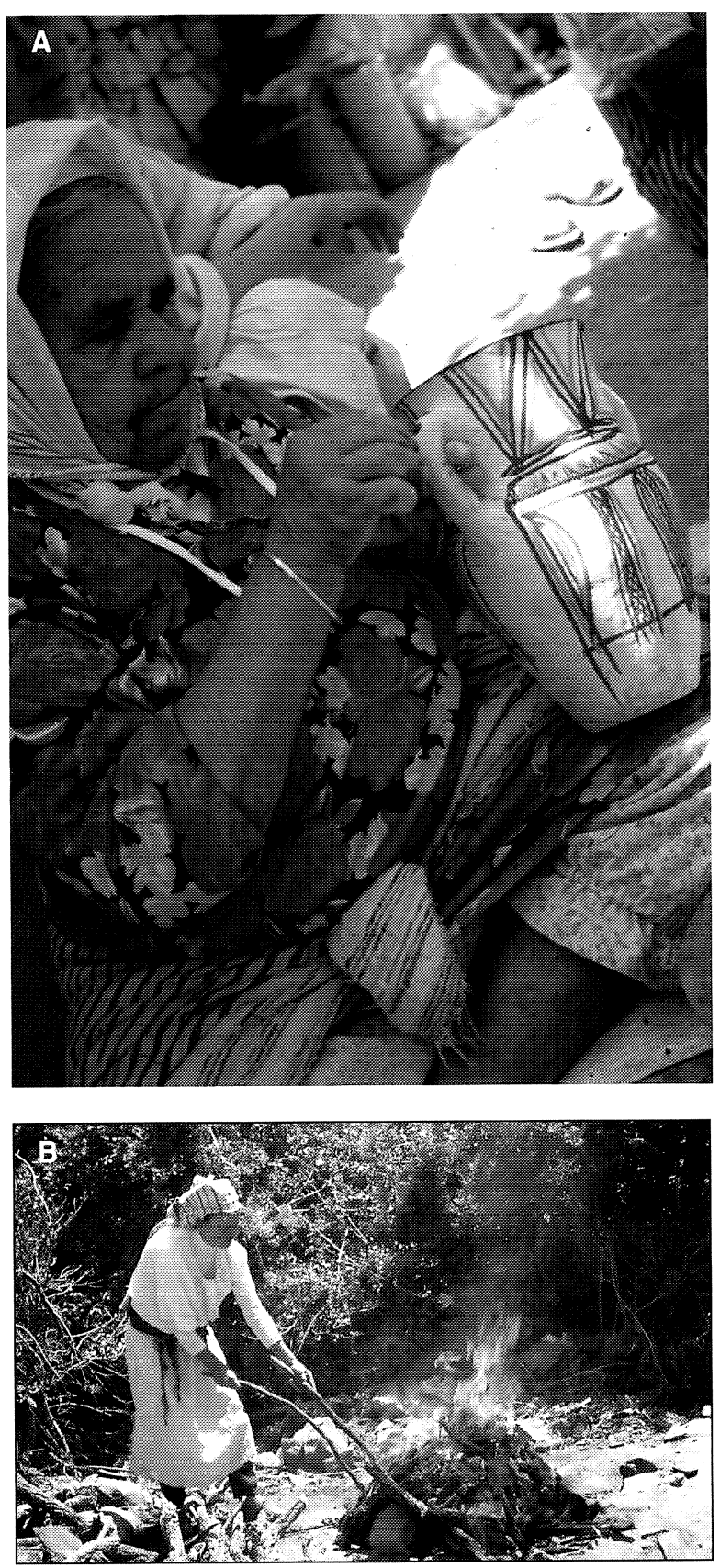

Lám. V. Decoración pintada de una pequeñaagattas, en Ain Kob (A) y cocción de la cerámica doméstica en El Aansar (B) (Rif occidental).

fuente; barrada, cántaros pequeños usados para contener agua y servir el agua; el halib, cuencos de pequeño/mediano tamaño empleados para ordeñar las vacas; y agattas, cántaros de boca ancha destinados a traer el aceite desde la almazara para almacenarlo en el interior de las casas.

\section{La cocción}

Existen diferentes técnicas de cocción de la cerámica. La técnica más sencilla consiste en utilizar el hogar doméstico (kanun). Este hogar doméstico está constituido por un pequeño agujero de unos 30 $\mathrm{cm}$ de diámetro, en el que se hace el fuego. El agujero sirve para conservar las brasas que, una vez tapadas con las cenizas, pueden aguantar encendidas hasta 24 horas. Distribuidas de forma regular alrededor del kanun se colocan 3 piedras que sostienen el recipiente cerámico en el que se cocina. En algunos lugares se utilizan prismas rectangulares con perforación central, hechos en barro no cocido, en sustitución de las piedras. Para la cocción de la cerámica se toman las 3 piedras del hogar y se sitúan directamente en el suelo del patio de la casa. Se colocan las cerámicas a cocer, una a una, sobre las piedras. Como combustible se utiliza leña menuda bajo la cerámica y corteza de alcornoque cubriendo el recipiente a modo de pira (Lám.VB). Esta técnica se emplea para cocer pequeñas cantidades de recipientes y está generalmente relacionada con la elaboración de cerámica que no es destinada a la venta en el zoco, sino para consumo de la propia familia o para intercambio con las vecinas del duar. Sin embargo, esto no siempre es así, puesto que en la aldea de Elaansar, en la cercana tribu Bani Idder, hemos visto esta técnica asociada a la producción del makla (platos para cocer pan) para la venta en el zoco. Cuando estas mujeres que elaboraban pequeñas cantidades de cerámicas para uso doméstico o para intercambio en el duar querían cocer cantidades mayores de cerámica utilizaban el horno de pan.

En general, la cerámica destinada a la venta en el zoco es cocida en hornos elaborados en hondonadas de 3 a 5 m de diámetro. En el ciclo de trabajo adaptado al zoco semanal, el horno se prepara el día anterior a la celebración del mercado.

El horno se dispone a unas decenas de metros de la casa, muy a menudo en zonas de ladera, siempre en el mismo lugar. Para prepararlo se ha excavado una suave hondonada circular, entre 20 y $80 \mathrm{~cm}$ de profundidad según la inclinación de la ladera (ver más adelante Lám. VI B). El hábitat de las aldeas es bastante disperso -estructurado según el principio de la 'discreción visual' (Boulifa, e.p.)- y debe guardarse un equilibrio en la localización del horno, que no debe estar demasiado próximo de las construcciones de la casa ni de las casas vecinas y a la vez lo bastante cercano para mantener cierto control, ante los riesgos de incendio o robo. Como 

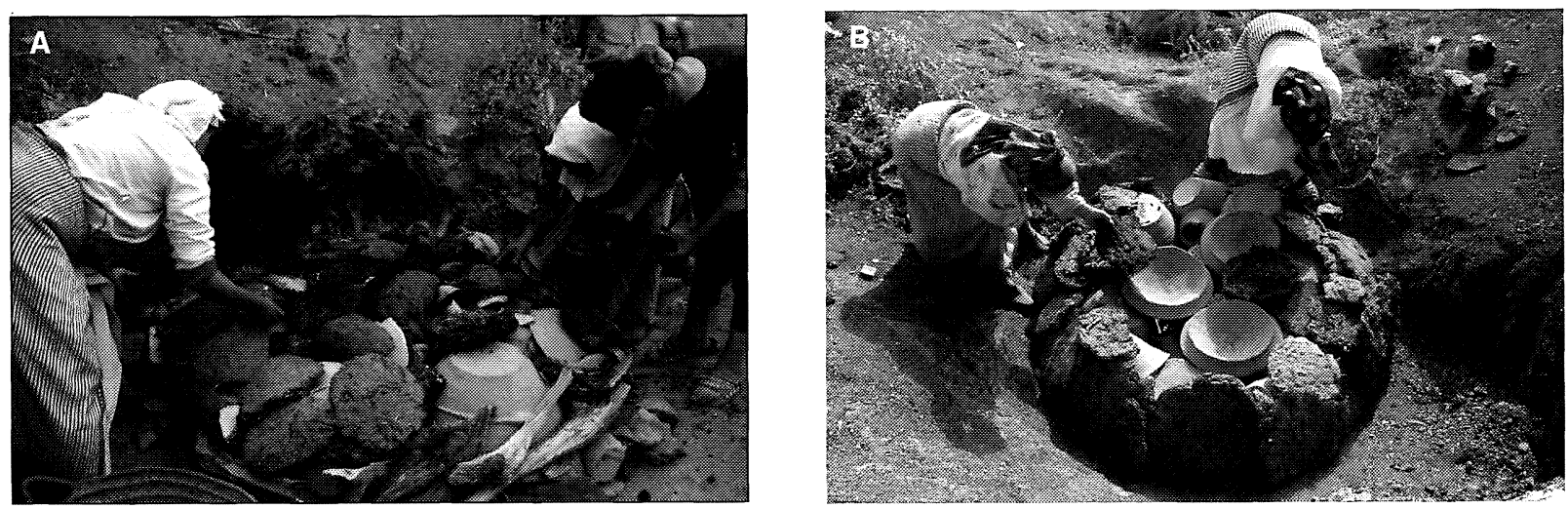

Lám. VI. Preparación del horno con tortas secas de estiércol, en Ain Kob (A) y Briet. Obsérvese en la parte derecha el corte producido por la excavación de la hondonada y en segundo plano la cárcava excavada por el arroyo (B).

combustible utilizan raíces y madera de árboles y arbustos. Los preferidos son la encina y el lentisco aunque también recurren a madera de acebuche, olivo, frutales (higuera, albaricoquero, etc...) o diversos arbustos. Procuran evitar la leña de fresno y sobre todo la de pino porque entienden que estas maderas dejan mates las superficies pintadas. Se aprovisionan de madera en los bosques cercanos. $\mathrm{La}$ madera se corta y trocea en el lugar de recogida, con un hacha, empleando a veces cuñas de piedra. Las mujeres transportan la leña a la espalda aunque en ocasiones cuentan con un animal de carga.

Para comenzar la hornada, se entrama con la leña y sus astillas la superficie circular del fondo del horno, rellenando los huecos con cuidado. Después, colocan las cerámicas sobre la madera. Los cuencos grandes abiertos para cocina se sitúan boca abajo, los pintados se colocan un poco inclinados, equilibrándose unos contra otros. En los márgenes de la plataforma se dispone un cinturón de leñas calzadas por el mismo reborde exterior del horno o con piedras y cascos de cerámica. Las bocas de los cuencos son tapadas con fragmentos de cerámicas rotas, para que no entren ascuas en ellas, ya que se podrían romper. Cubren las cerámicas con una capa de tortas hechas con boñigas secas de vaca o de cabra (Lám. VI) y posteriormente con otra capa de estiércol fresco, cuya función consiste en evitar que el fuego sea muy vivo y conseguir que el calor se distribuya regularmente. Las boñigas que se utilizan se han amasado y dejado secar en forma de tortas en las semanas anteriores; en este tiempo también se va acumulando el estiércol fresco que se emplea en el horno. En una hornada en la que cuecen unas pocas decenas de recipientes son necesarios cerca de 250 kilos de estiércol. Encienden la estructura por tres puntos, introduciendo ramitas encendidas en huecos que han dejado en la base. Cuando el fuego ha prendido tapan los puntos de encendido con fragmentos de estiércol seco. A medida que él horno se quema van regulando la intensidad de la cocción añadiendo boñigas secas o estiércol fresco en los huecos por donde surgen llamas.

Esta fase de la fabricación se concibe como un momento crítico y se percibe la mayor tensión y concentración de las artesanas. Es preciso controlar la temperatura que alcanza el horno, apagando las llamas vivas, ya que un exceso de temperatura puede fracturar las cerámicas. Las ceramistas temen también la aparición del viento y de la lluvia, factores que pueden modificar o descontrolar la temperatura del horno.

El tipo de combustible empleado y su disposición condiciona la temperatura del horno, que debe

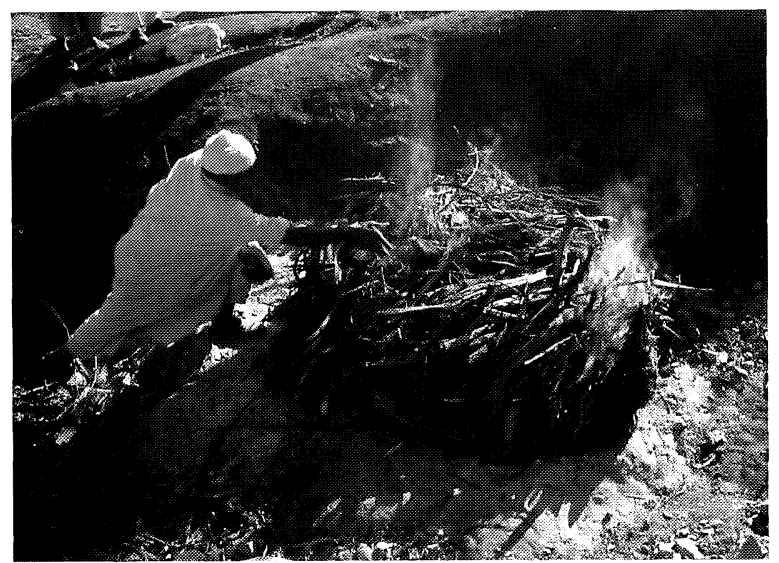

Lám. VII. El final de la cocción en Ain Kob. 
estar relacionada con las características de la arcilla empleada en cada aldea. Así existen variables en este aspecto en los diferentes lugares de fabricación. En Dahar cubren la cerámica con madera y encienden la pira, sobre la que echan estiércol seco media hora después de que el fuego esté en marcha por lo que durante la fase inicial el fuego es muy vivo. En Briet prefieren la madera de higuera, ya que el empleo de maderas con mayor poder calorífico fractura las cerámicas.

Las cerámicas para agua, hechas sólo con arcilla blanca y desgrasantes, necesitan mayor temperatura y tiempo de cocción que las culinarias, hechas con arcilla roja, blanca y desgrasantes. Para conseguir atender a los dos tipos de cerámicas en la misma hornada siguen dos estrategias diferentes. En algunos casos colocan las cerámicas para agua en el centro del horno, donde se alcanza más temperatura. En otros, ordenan las cerámicas en dos secciones de la hornada y atienden durante más tiempo, añadiendo combustible, la zona donde se encuentran los recipientes para agua.

El horno se consume durante varias horas y se deja toda la noche para que se enfríe. El mismo día del mercado se retiran las cerámicas con cuidado, pues aún están calientes. Después se llevan a la casa $\mathrm{y}$, una vez que han perdido calor, se van mojando con agua, lo que es bueno para asegurar la resistencia de las cerámicas, y para evitar que estallen los desgrasantes calizos y se piquen las paredes de los vasos. Las cocciones a las que asistimos fueron satisfactorias en general, pues no hubo fracturas y los cuencos estaban regularmente cocidos, excepto en el caso de Briet donde se apreciaban fisuras entre el 10 y el 20\% de las piezas. Éstas son corregidas con una masa en la que se mezcla cal, leche y cemento, si la grieta se encuentra en el exterior, o cal y leche, si se quiere reparar el interior del cuenco, evitando así el contacto del cemento con los alimentos. Como aglutinante, también se puede utilizar la yema de huevo en vez de la leche.

En el pasado, cuando había más ceramistas en la región, la cocción podía ser comunal, en un espacio cercano al centro de la aldea. Allí podían cocer la producción 4 ó 5 mujeres cada vez. Después cada una se encargaba de la venta de sus cerámicas por separado. Todas las artesanas se ocupaban de aportar la leña y el estiércol para el fuego. En el horno común podían hacer hasta 60 grandes cántaros para agua en la misma hornada.

Algunos de los tipos de horno que hemos descrito dejan pocos vestigios arqueológicos. La cocción en el hogar doméstico o en el horno de pan no deja resto identificativo alguno de la producción de cerámica en el lugar. Las estructuras de horno en hondonada son algo más evidentes. Después de que se han retirado las cerámicas quedan, además de la hondonada del horno, restos de los carbones y las cenizas, fragmentos de las cerámicas rotas durante la cocción o las usadas para tapar las bocas de las cerámicas y una orla de piedras en los márgenes interiores de la hondonada, las que han sujetado la estructura de combustión. Cada vez que se quiere reutilizar el horno se limpia la hondonada y se desplazan los restos de la cocción anterior por la pendiente. Sin embargo, los usos repetidos van creando una superficie en la base del horno, dura, regular y ligeramente rubefactada. En Dahar y Briet aprovechan las cárcavas secas de los arroyos durante el estiaje para acondicionar el horno lo que aumenta la invisibilidad arqueológica de estas estructuras que son regularmente erosionadas en la época de lluvias.

\section{El objetivo de la producción: cerámicas culinarias y contenedores pintados}

Dentro del esquema de producción para autoconsumo o venta en el duar sólo se produce una limitada variedad de cerámicas culinarias no decoradas: gedras (cacerolas), mishmar (braseros) y makla (platos de cocción) de pan y de ergaif, el pan ácimo. En algunos casos esta variedad es aún más reducida, limitándose a la producción de makla de pan. La cantidad de producción de cada ceramista era muy escasa, entre 5 y 30 cacharros por año. Cuando la producción se distribuía, el intercambio tenía lugar en el ámbito del propio duar, generalmente con las vecinas, y por el sistema de trueque. Es una opinión extendida que la calidad de estas cerámicas es peor que la que producen las artesanas que acuden al zoco.

En la producción para venta en el zoco la variedad es mayor. Dentro de la cerámica culinaria, hemos observado la producción de: sahba o sahfa (cuencos grandes de paredes abiertas, que se usan para amasar el pan y preparar la sémola del cuscús), slafa (platos para comer), mishmar, quemadores para cocinar sobre las botellas de gas; recipientes en forma de botella donde se hace fuego para espantar a las abejas cuando se recoge la miel, gedra, keskes (cuencos con la base perforada para la cocina a vapor), tayin (cuencos planos y redondos para cocinar); makla de pan y de ergaif, etc. 
La cerámica pintada está destinada a contener líquidos (aceite, agua o leche). La mayor parte de las formas que se elaboran son cántaros o vasijas, de diferentes tamaños: agattas (contenedores para aceite de hasta 30 litros), asakai o heber (recipiente de dos asas con el que las mujeres van a la fuente a recoger el agua), barrada (recipiente para contener agua con 2 ó 3 litros de cabida) y el-halib (cuenco para ordeñar). También se fabrica elfjajar, vasijas de gran tamaño para almacenar aceite que se embuten en el suelo de las casas y que no están pintadas. Entre las cerámicas pintadas aparece un tipo particular formado por dos pequeñas vasijas geminadas. Los informantes afirman que se trata de formas sin función concreta, destinadas a la decoración. Sin embargo, G. Camps (com. pers.) ha comprobado en otras zonas que se trata de cerámicas con significado simbólico, relacionadas con el matrimonio. Es posible que se trate de un significado que se ha perdido entre las artesanas actuales.

\section{ASPECTOS ECONÓMICOS Y SOCIALES DE LA PRODUCCIÓN CERÁMICA}

Trataremos aquí el contexto económico y social de la producción cerámica y observaremos por un lado cómo se relaciona con las técnicas de producción y, por otro, qué implicaciones tiene para comprender comportamientos prehistóricos. Se abordarán en apartados sucesivos las cuestiones relacionadas con las formas de distribución de los productos, el aprendizaje y la transmisión de las técnicas, el significado de las decoraciones, la organización del trabajo y los procesos de cambio, haciendo especial hincapié en la cuestión de la especialización artesanal.

\section{La distribución de los productos}

La principal forma de distribución ha sido la venta o trueque en el zoco semanal; hemos visto que esta orientación hacia el zoco determina la organización del trabajo durante la semana de modo que la última fase de trabajo, la cocción de los recipientes, se hace el día anterior. En el zoco la cerámica era vendida directamente por la ceramista. Era común que las artesanas de diversos pueblos se agruparan en una zona concreta del zoco, donde solían intercambiar ideas sobre las técnicas o recibir inspiraciones sobre los motivos decorativos.Las cera- mistas acudían habitualmente al zoco de Mokrisset, el que corresponde a la fracción Bani Chaib, donde se incluyen la mayor parte de las artesanas, pero también llevaban piezas a otros zocos cercanos fuera del territorio tribal -en Suk el Had y en Fifi.

En el pasado había otros sistemas de intercambio. Dos eran las posibilidades, tanto para la cerámica pintada como para la culinaria. Bien la gente de los alrededores venía a encargar y comprar la cerámica o a trocarla en la aldea de la especialista; bien los varones de la familia de las artesanas viajaban con la cerámica para distribuirla. Los viajes se hacían en verano, una temporada propicia porque es el momento en el que se fabrican los recipientes, los clientes disponen de los productos de la cosecha para el trueque y los caminos están secos y practicables. Eran viajes de 2 ó 3 días de duración, en los que llegaban a zonas alejadas hasta $30 \mathrm{~km}$ del lugar de origen $-7 \mathrm{u} 8$ horas a pie. Los criterios para dirigirse a unas regiones $\mathrm{u}$ otras se basaban (1) en lá abundancia de cereales, o de productos agrícolas en general, en las comarcas de destino y (2) en la ausencia de competidores. Así, por ejemplo, nunca viajaban al sur de Zumi, pues en esta zona se encontraban con las ceramistas de Bani Mesgilda. Normalmente no acudían hacia la región de Ketama, al este, donde la producción agrícola es más limitada. En cualquier caso, las fronteras de la propia tribu no representaban un límite a la venta itinerante.

A menudo el valor del trueque consistía en la cantidad de cereal o legumbres que cabía en el recipiente. En los años de malas cosechas, el cántaro se llenaba aún menos. En otras ocasiones el trueque se hacía por habas o frutas. También podían realizarse trueques más complejos: las cerámicas por tejidos o sal en las aldeas donde se elaboraban (un cántaro pintado de 10 litros de capacidad equivalía a unos 4 kilos de sal) y estos artículos se cambiaban más tarde por los productos agrícolas. En estos desplazamientos se llevaban más a menudo las cerámicas pintadas, de fabricación más compleja, para las que había una mayor demanda ya que la producción de cerámica culinaria era más ubicua. Todos estos buhoneros tenían como objetivo preciso la obtención de productos alimenticios que compensaran la escasez de la producción familiar.

Las mujeres también podían ejercer de vendedoras itinerantes, pero en este caso se trataba de trayectos cortos, volviendo a casa en el mismo día. La propia alfarera también podía transportar la cerámica hasta el comprador, en caso de encargo. En una 
de las casas de Teiyut, aldea situada $8 \mathrm{~km}$ de Briet, encontramos un elfjajar de gran tamaño que procede de Briet. Lo había transportado la propia alfarera, cargado a la espalda.

Las cerámicas Gzaua llegaban a los consumidores por muy diversos mecanismos, una variabilidad en los intercambios que es bien conocida ( $c f$. Renfrew, 1977: 9-10; Rice, 1987: 192-194). Esta diversidad de sistemas de intercambio genera patrones muy complejos de dispersión de los productos. Con respecto a estos sistemas de distribución de las cerámicas, el análisis de procedencia de las pastas podría discriminar las producciones para autoconsumo o intercambio en el duar, por una parte y los de ámbitos de venta más extensos por otra. El intercambio preferente de las cerámicas en el zoco implica un patrón de dispersión concéntrico, dentro del ámbito de influencia de dicho zoco. La fabricación y uso de la cerámica en el lugar de producción y la distribución minorista en los duares vecinos generará un área de concentración en y alrededor del duar de producción. Algunas cerámicas, por medio de los vendedores itinerantes, pueden llegar hasta 30 o $40 \mathrm{~km}$ del lugar de producción; este tipo de distribuciones que implican un cierto nivel de especialización regional reflejan una forma de intensificación económica y están en la raíz del establecimiento de relaciones del tipo centro-periferia (cf. Shennan, 1999: 354). Como ya ha sido señalado en otros estudios etnográficos, las morfologías de recipientes y principalmente las decoraciones, permiten identificar colectividades, en este caso duares y tribus, pero sólo en el contexto de producción y no en el contexto de uso, puesto que las cerámicas se intercambian con criterios pragmáticos (Hodder, 1977: 269; Reina y Hill, 1978: 216; Dietler y Herbich, 1994a).

\section{El aprendizaje y la transmisión de las técnicas}

El proceso de aprendizaje (Wallaert-Pétre, 1999) suele llevarse a cabo en el seno de la familia. Las aprendizas van conociendo la técnica desde niñas, colaborando con las especialistas adultas de la familia. Estas niñas inician el proceso de aprendizaje hacia los 10 u 11 años, dentro de la biografía típica de las mujeres en la sociedad gzauí, que prescribe que las niñas de menor edad se ocupan principalmente del cuidado de los animales. Se inician en tareas auxiliares como la preparación de la arcilla y más tarde en la decoración de los recipien- tes, en la fabricación de las formas más pequeñas y sencillas y de aquí pasan a la fabricación de formas complejas, principalmente las que tienen cuello, y al control de la cocción de la cerámica. Algunas mujeres aprenden cerca de una vecina si no tiene familiares que conozcan el trabajo. En este caso, la aprendiza trabaja con la maestra, que es normalmente alguna de las mujeres que tienen más prestigio en la aldea por la calidad de su producción. $\mathrm{La}$ maestra acepta a las aprendizas sin restricciones, y sin recibir ningún beneficio apreciable por la enseñanza. Toda la cerámica que elabora la aprendiza durante el proceso de formación revierte en su propio beneficio, es ella quien la vende directamente. El tiempo de aprendizaje se extiende a lo largo de uno o dos años. Según las informantes, todas las fases del trabajo presentan igual dificultad. Sin embargo, hemos apreciado claramente la mayor dificultad que supone la elaboración de la parte superior de los recipientes ( $c f$. Gelbert, 1999: 222 para una observación similar). Así, mientras no dominan completamente la técnica, las aprendizas realizan solo las formas cerámicas más sencillas, las abiertas, evitando los vasos cerrados con cuello y, en general, los de gran tamaño. También destaca lo delicado de la fase de cocción, puesto que, si no se controla bien, las piezas se pueden fracturar.

Además de la enseñanza entre las mujeres en la misma comunidad, otro mecanismo de transmisión de la técnica (Gelbert, 1999) se produce a partir del matrimonio, dentro de una estructura social virilocal (Dietler y Herbich, 1994b). Se trata de mujeres que aprenden la técnica cuando se casan con un hombre residente en una aldea donde se fabrica cerámica. A diferencia del aprendizaje entre las niñas, el de las mujeres adultas se realiza reproduciendo el proceso desde las primeras fases hasta la cocción y aprendiendo el conjunto de la técnica de forma simultánea. Hemos apreciado que algunas familias no enseñan a sus hijas las técnicas artesanales desarrolladas en el duar de origen dado que son conscientes que es probable que no les sean de utilidad después del matrimonio.

Existen una serie de limitaciones sociales que dificultan la transmisión de las técnicas y los motivos decorativos de una aldea a otra. En caso de que una mujer sea ceramista en su pueblo de origen, cuando va a residir tras el matrimonio a otro pueblo donde se fabrica cerámica abandona las modalidades aprendidas y adopta las de la aldea de acogida. Los mecanismos de socialización de las mujeres dentro de la estructura social virilocal que limitan

T. P., 58, n. ${ }^{\circ} 1,2001$ 
las posibilidades de transmisión de las técnicas (Dietler y Herbich, 1994b), justifican el hecho de que la producción cerámica quede circunscrita a pocas aldeas y que cada una de ellas mantenga su propia tradición formal y decorativa.

No parece común el caso de mujeres de estas aldeas ceramistas que transmiten la técnica a lugares donde no se conoce. En general, las mujeres abandonan la fabricación cuando se casan y van a vivir a otra aldea donde no se produce cerámica. Hay varias razones que explican la dificultad en la expansión de una técnica. La razón que aducen las mujeres es la ausencia de arcillas en las cercanías de su nueva residencia. Sin embargo, hay algo más que esta razón. Hemos conocido algunos casos de mujeres que encontraron arcilla en los pueblos de acogida y siguieron trabajando la cerámica. Estas artesanas reproducían las técnicas aprendidas antes del matrimonio. En todos los casos que hemos conocido, la razón para esta continuidad se basa en la necesidad de aportar ingresos ante la pobreza de la familia recién formada. Estas mujeres abandonaron la técnica al cabo de un tiempo, o, si han continuado, no han transmitido sus conocimientos a sus hijas u otras mujeres. Justifican este hecho en el desinterés de los hombres por la cerámica, por lo que no les prestan ayuda. Entendemos que se refieren básicamente al conjunto de la división sexual del trabajo, al reparto de las tareas cotidianas. Aunque no lo hemos podido registrar con precisión suponemos que en los pueblos ceramistas el reparto del trabajo entre hombres y mujeres tiene en cuenta la dedicación de éstas a la cerámica, lo que probablemente no es socialmente reconocido en los pueblos no ceramistas, donde las mujeres se dedican aún con mayor intensidad a las labores agropecuarias. A este respecto, en una aldea nos manifestaron que si las mujeres continuaran con la cerámica en sus nuevos duares, ellas llevarían todo el peso del trabajo y los maridos no harían nada (5).

Aceptando estas barreras sociales que dificultan la transmisión de conocimientos entre aldeas, ¿cómo se han producido estos intercambios que son evidentes en las características generales de la cerámica de la región? Conocemos casos de intercam-

(5) La división del trabajo entre los gzauíes es muy desequilibrada. Las mujeres se encargan de la mayor parte de las actividades agrícolas, ganaderas y artesanales, del acarreo del agua y de la leña y de las labores domésticas -limpieza, cocinado, cuidado de los niños, etc... Los hombres se ocupan de algunas artesanías -cestería, peletería, trabajo del hierro-, del molido de la aceituna, de la preparación de las tierras cultivadas o de la construcción de las casas. bios de experiencias entre ceramistas de diferentes pueblos, durante los contactos que se producían cuando acudían a recoger arcilla blanca en las minas. Así, las mujeres de Saara copiaron motivos decorativos de las de Ain Kob.

El zoco ha jugado un papel muy importante en la transmisión de las técnicas, tanto por suponer un ámbito de contacto entre ceramistas de diferentes pueblos, como por el hecho de que el mercado supone la sobrevaloración de ciertas producciones con respecto a otras. El mejor ejemplo lo hemos encontrado entre las tribus situadas al sur de los Gzaua. Así, los guembura (cántaros de agua) de Slit adquirieron prestigio y un alto precio en el zoco, por lo que artesanas de otros pueblos de la misma tribu (Mrila, de los Bani Mesgilda) o de otra tribu (Gsira, de los Bani Mestara) copiaron las formas y decoraciones de Slit. También hemos conocido casos de artesanas que copian modelos de cerámicas que compraron en el zoco. A veces se trata de piezas elaboradas con técnicas muy diferentes (a torno, vidriadas o piezas de metal), por lo que se copia es el diseño que permite la función (6) o algún aspecto de la decoración. La transmisión de esquemas formales o decorativos entre duares tiene lugar por la copia de los modelos que han adquirido prestigio por su calidad o belleza. El papel del zoco como dinamizador de esta transmisión es importante.

\section{El significado de las decoraciones}

Normalmente cada mujer decora su propia cerámica, aunque hemos observado casos de mujeres que pintaban recipientes elaborados por otras, a cambio de un pago. Dentro de las ceramistas que hacen cerámica pintada se aprecia a las mejores decoradoras. En Ain Kob distinguían apenas 4 buenas pintoras cuando había entre 15 y 20 ceramistas en la aldea.

Las ceramistas del Rif realizan decoraciones complejas y estereotipadas, lo que inmediatamente evoca el problema del posible significado de los motivos representados. Ante esta pregunta directa, la respuesta que se obtiene de las ceramistas es siempre la misma: se trata sólo de decoración; es para que se venda mejor en el zoco.

El acercamiento realizado hasta ahora nos permite tan solo señalar algunos aspectos de este tema

(6) Hemos visto copias de mantequilleras y de quemadores para bombonas de gas 
complejo. Las cerámicas pintadas en las sociedades del Rif occidental presentan diferentes ámbitos de significado. En primer lugar, reflejan rasgos de la identidad a diferentes niveles: tribal, local e individual. La decoración de los recipientes con una base de colorante blanco, bandas de color negro en la zona alta del cuello y trazos negros y rojos es similar a la que presentan otras tribus, como los Bani Mesguilda, Bani Zerual o El-Ahmas, al N. y al S. de Gzaua. Sin embargo, las decoraciones de cada tribu presentan peculiaridades que permiten identificar su origen. Además, las decoraciones de cada tipo de recipiente están estereotipadas dentro de cada duar, constituyendo microestilos decorativos (Dietler y Herbich, 1994a: 465). Todas las mujeres del duar siguen los mismos esquemas decorativos generales, variando sólo detalles complementarios, que reflejan elecciones individuales. Estas decoraciones compartidas son reflejo y elemento potenciador de la solidaridad de los miembros de la aldea, aspecto que está bastante desarrollado en otras instituciones de ayuda mutua.

Sin embargo, es necesario señalar que estos caracteres de identidad se corresponden con el contexto de producción, pero no con el contexto de uso de los recipientes (Dietler y Herbich, 1994a; Gallay et alii, 1996). Las cerámicas decoradas se destinaban a la venta, transpasando los límites del duar, de la fracción, e incluso de la tribu. Como hemos visto, en el pasado era corriente encontrar cerámicas Gzaua entre tribus vecinas, que habían sido compradas en el zoco o a vendedores itinerantes.

En segundo lugar, el uso de cerámicas pintadas frente a las no decoradas era reflejo de estatus social. En Ain Kob afirmaron que en el pasado se fabricaban las mismas formas cerámicas que las pintadas, pero sin decorar, para las familias más pobres. Las cerámicas no decoradas se utilizaban a diario para actividades desarrolladas en el interior de la casa, incluso en las casas de las ceramistas, mientras que las pintadas se mostraban en fiestas desarrolladas en el ámbito doméstico o cuando venían visitantes a la casa. Entre las mujeres que iban a la fuente a recoger agua había una cierta competencia por llevar los cántaros mejor decorados. La señora Mnana, una de las artesanas deAin Kob, señalaba que, cuando vivía con sus padres en Dar Hok, ella y su hermana recibieron como regalo sendos asakai decorados para que fueran a la fuente, lo que le parecía una expresión de hasta qué punto su padre las mimaba.

Losbarrada pintados, jarras pequeñas para servir el agua en la mesa, además de su función cotidia- na cumplían otras de carácter simbólico. Durante los esponsales, en un sistema virilocal que implica a menudo el desplazamiento de la mujer a otro duar, la novia llevaba a casa del marido un barrada con agua de su aldea de origen. En otros pueblos no llevaban agua de la aldea de origen, sino sólo el recipiente. La madre de la novia era la que se ocupaba de encargar y pagar la cerámica, que debía ser nueva. El recipiente se guardaba en la habitación del matrimonio y bebían ambos cónyuges de él durante 7 días. La mujer permanecía recluida en la habitación durante esos siete días, al término de los cuales ya era considerada como parte de la nueva familia. La esposa estaba atenta a que el barrada contuviera siempre agua. Como ella no podía salir de la habitación pedía a la suegra que aportara el agua. Al beber del mismo agua se aseguraban que nadie hiciera magia que separara al matrimonio. Después de los siete días el barrada era entregado a la mezquita. En los últimos años esta práctica ha caído en desuso, pero hasta hace pocas décadas era común en todas las aldeas de la zona de Mokrisset, y, también entre otras tribus del Rif. En la actualidad, en algunos pueblos, se ha sustituido el barrada por una tetera metálica.

Otros barrada decorados se utilizan también en contextos con fuerte carga simbólica. Cerca del único santuario situado en el territorio de la fracción Bani Chaib (el de SidiAbderrahman) hay una fuente de agua, a la que se atribuyen cualidades curativas. Los habitantes de la aldea más cercana llenan con agua de la fuente un barrada decorado y la colocan en el santuario a los pies de la tumba del santo, para que beban los devotos. El uso del barra$d a$ en este contexto resulta llamativo ya que hoy en día no se emplean las cerámicas pintadas en los ámbitos domésticos.

Estas referencias sugieren que el sentido de la decoración no reside exclusivamente en el deseo de facilitar la venta para el vendedor y reflejar un estatus social para el comprador, cuando la utiliza en ámbitos públicos. Resulta evidente que la decoración pintada se relaciona con el hecho de que el recipiente contenga líquidos, sean éstos el agua, el aceite o la leche. Los casos de los barrada nupciales y del barrada del santuario parecen sugerir que las decoraciones tienen un sentido apotropaico, en relación a las cualidades positivas del líquido que contiene. ¿Es posible proyectar este valor a toda la cerámica pintada entre los Gzaua? Esta función simbólica de la decoración cerámica no puede ser expuesta por el momento más que como una hipótesis, a falta de una contrastación más específica. 


\section{La organización social del trabajo y la especialización artesanal}

La elaboración de la cerámica es un trabajo especializado, llevado a cabo por un número limitado de artesanas, que han pasado por un proceso de aprendizaje que no siempre se desarrolla en el ámbito familiar. No es, por tanto, un conocimiento técnico general, sino especializado. Sin embargo, su dedicación a esta tarea es limitada y subordinada en relación con el conjunto de labores que ellas desempeñan. Es un trabajo casi siempre veraniego, siendo muy marginal en invierno. Además, estas mujeres atienden también el conjunto de labores domésticas, agrícolas y ganaderas, necesarias para la subsistencia de la familia.

Es una actividad exclusiva de las mujeres. Ellas recogen la tierra, la preparan, elaboran las vasijas, las decoran, las cuecen y las distribuyen en el mercado. Sin embargo, en el pasado, cuando la producción era más intensa, las mujeres podían contar con la colaboración puntual de los hombres en tareas poco especializadas que exigieran esfuerzo físico, como la recogida de la leña destinada a alimentar la cocción. También la distribución en áreas lejanas, que requerían pernoctar fuera de la casa, era una función masculina.

En Dahar hemos tenido ocasión de observar cómo se adapta la organización social del trabajo a la necesidad de intensificar la producción. En el último año, una de las ceramistas ha recibido un encargo inhabitual de un mayorista de Tánger -600 cántaros-por encima de su capacidad de producción en condiciones normales. En estas circunstancias, la artesana se ha concentrado en las fases del procesado que llevan desde la preparación de la pasta hasta la cocción mientras su marido se ha encargado de la obtención de las materias primas -las arcillas y la leña-, y ha colaborado en la preparación del horno y en los desplazamientos de los recipientes entre las distintas áreas de trabajo; también se ha encargado de buena parte de las labores domésticas. Resulta destacable que una solución muy parecida en el reparto del trabajo se ha alcanzado en otros lugares del Rif occidental-como en Ued Lau-donde se ha desarrollado una producción intensiva de cerámica por urdido forzada por una explotación a mayor escala que compite incluso en los mercados urbanos.

En términos globales, las artesanas actúan individualmente. Sin embargo, esta afirmación debe ser matizada, puesto que hemos visto varios ámbitos en los que se producía colaboración entre artesanas, como el trabajo colectivo para la elaboración de la mina de arcilla en Ain Kob, la recogida de la tierra o la cocción.

En ocasiones, mujeres de la aldea que no saben hacer cerámicas también colaboran en las tareas que requieren menos destreza, como ayudar a recoger la tierra, llevar las piezas al sol para que se sequen, moler los colorantes, o transportar las piezas al lugar donde se va a construir el horno de cocción, a cambio de un pago o participando en el reparto de la producción. Las artesanas también son ayudadas por las mujeres jóvenes de la casa en este tipo de labores; la colaboración constituye una forma de aprendizaje. El conjunto de mujeres de la unidad familiar también colabora indirectamente liberando a las ceramistas de una parte de las actividades domésticas.

A pesar de la estructura igualitaria de la producción, existía una cierta jerarquía entre las artesanas, que se basabá en el prestigio conseguido por la calidad de la producción de algunas de ellas. Estas ceramistas prestigiosas ejercían más influencia a la hora de tomar decisiones colectivas, como las referentes a la mina de arcilla, o a la hora de transmitir la técnica a las aprendizas.

En el Rif occidental se llega a la especialización artesanal a través de la precariedad económica, lo que ya ha sido observado en otros estudios etnográficos sobre fabricación cerámica (Rice, 1981; Arnold, 1985). En general, la alfarería es una actividad de mujeres pobres, pertenecientes a familias que tienen dificultades para conseguir los bienes apreciados-generalmente por falta de tierras-, que son los productos agrícolas y ganaderos. La fabricación cerámica representa una respuesta a la escasez de estos recursos, principalmente cereales, como se puede comprobar en los trueques. Los cereales forman la base de la dieta y se aprecian por la posibilidad de almacenamiento y consumo diferido. Incluso para las ceramistas la producción agrícola es prioritaria; la alfarería se pospone o incluso abandona cuando el trabajo en el campo es intenso.

Desde luego, los artesanos no se constituyen en actores políticos que consiguen algún tipo de preeminencia social a través del control de la distribución sino que se encuentran en una clara situación de desventaja en los intercambios ( $c f$. Shennan, 1999). Esto se observa en el bajo precio que consiguen para sus piezas y en la constatación de que el trueque está condicionado por el valor de las cosechas anuales. En algunos casos, tanto para ceramis- 
tas como para otros artesanos, hemos apreciado que los campesinos un poco más acomodados encargan o adquieren algún bien, sin una necesidad estricta o incluso teniendo capacidad para producirlo por sí mismos, sólo con el objetivo de ayudar económicamente a los artesanos, a quienes se percibe como pobres y necesitados. Ya hemos mencionado la existencia de abundantes normas e instituciones de acuerdo y ayuda mutua, más allá de las estrictamente musulmanas, como la tawaza, el lausiah-gorah o el ezart (7). Esta situación parece atenuada en los lugares donde hay numerosas ceramistas que producen cerámicas decoradas para la venta en el mercado. Es probable que la producción de cerámicas de calidad, especialmente pintadas, haya supuesto una vía de promoción económica, en parte relacionada con la incipiente demanda turística.

El mismo fenómeno se reproduce a escala regional. Las montañas rifeñas presentan malas condiciones para los cultivos lo que ha generado un gran desarrollo de las artesanías (de las cesterías, la piel, el hierro, etc...). Es característico el esfuerzo de los buhoneros que distribuyen las cerámicas por alcanzar las regiones ricas en cereales, que pasan a ser el objetivo principal de los intercambios. La especialización artesanal se convierte por esta vía en una forma de intensificación económica regional (Shennan, 1999: 353).

Si entendemos el artesanado como una producción de especialistas destinada al intercambio, queda por aclarar hasta qué punto la producción cerámica gzauí implica una producción artesanal. Se han estudiado algunos ejemplos etnográficos de producciones cerámicas para autoconsumo por parte de ceramistas no especialistas, que comparten un conocimiento general a todas las mujeres del grupo (Longacre, 1981). De hecho, la producción cerámica femenina en el Magreb ha sido caracterizada como estrictamente doméstica (Balfet, 1965; Picon, 1993), como una producción femenina que se destinaría al autoconsumo de la unidad familiar. Se ha descrito como un conocimiento técnico general entre las mujeres de la región, que emplean técnicas muy sencillas, con una escasa selección de las arcillas y cocciones poco cuidadas.

Nuestras observaciones en el Rif occidental no encajan con este esquema. Hemos observado procesos técnicos para la elaboración de recipientes

(7) González Urquijo, J.; Ibáñez, J.J.; Moreno, M.; Peña-Chocarro, L. y Zapata, L. (1999): Las primeras comunidades campesinas. El aporte de la etnoarqueología en Marruecos. Memoria presentada ante la Fundación M.Botín. que eran conocidos y practicados por todas las mujeres de la región, en un ámbito estrictamente doméstico, pero en estos casos se trata de los recipientes en estiércol de vaca y/o arcilla no cocida, empleados para el almacenaje del grano (Ibáñez et alii, e.p. a). Sin embargo, la fabricación cerámica no sigue este modelo. El único caso que hemos conocido de fabricación cerámica para autoconsumo se refiere a una mujer que trabajaba de ayudante de otra ceramista, por lo que puede tratarse de una situación favorecida por ese particular. Entre las mujeres más ancianas no hay recuerdo de que la generalidad de las mujeres Gzaua fabricara cerámica. Siempre ha sido un trabajo de especialistas, que se han sometido a un proceso de aprendizaje que no siempre se desarrolla en el seno de la propia unidad familiar, pudiendo ser definido este proceso técnico como de artesanía doméstica (Peacock, 1982: 8; van der Leeuw, 1984; Rice, 1987: 184). Es un trabajo exclusivamente de mujeres, que trabajan individualmente. La actividad es a tiempo parcial, pues se concentra fundamentalmente en el verano, $y$, en esta estación, ocupa algunas horas al día. Las artesanas, además del trabajo de ceramistas, se dedican a las labores domésticas y a la explotación de los recursos agrícolas y ganaderos. El proceso técnico no implica la existencia de estructuras constructivas estables, tales como taller, almacén u horno. La producción es limitada, en el mejor de los casos, alrededor de 15 cuencos grandes por semana, llegando hasta 30 si se trata de vasos más pequeños. Es difícil calcular la producción anual de estas ceramistas, aunque sin duda debía contarse en centenares. La distribución se lleva a cabo directamente por las ceramistas en el propio duar o en el zoco, vendiéndose la cerámica en un área geográfica restringida; el trueque ha constituido un mecanismo fundamental de intercambio. En caso de que sean comercializados por vendedores itinerantes los recipientes raramente se distribuyen a más de 20 ó 30 km del lugar de producción.

Dentro de esta producción artesanal hemos observado dos esquemas productivos diferentes, con ciertas implicaciones en las técnicas empleadas. La existencia de minas de arcilla, la mezcla de diferentes arcillas en un mismo vaso, el cribado de las arcillas, la elaboración de formas cerradas con cuello, el uso de hornos para la cocción de grupos de cerámicas y las decoraciones complejas estandarizadas son elementos relacionados con el esquema productivo que lleva a la distribución de la cerámica en el zoco o a largas distancias. Algunos aspectos, como

T. P., 58, n. $^{\circ} 1,2001$ 
la mina o el horno de cocción de múltiples vasos son reflejo de un deseo de intensificar la producción. La elaboración de vasos altos y cerrados, con cuello, refleja un alto grado de destreza técnica que sólo puede conseguirse con una práctica continuada. El mantenimiento de decoraciones estandarizadas complejas sólo puede entenderse en un contexto de producción, el duar, que agrupe a un número alto de artesanas, e implica una práctica continuada que justifique la pervivencia de los modelos.

Estos rasgos no aparecen en el otro modelo productivo, en el que la cerámica sirve para las necesidades familiares o se distribuye en el interior de la misma aldea, con producciones que a veces no superan las 30 piezas por año. Sin embargo, sí puede ocurrir lo contrario ya que hemos observado el uso de técnicas muy sencillas (sin mezcla de arcillas, elaboración de cuencos bajos y abiertos; cocción una a una en el kanun, etc.) para fabricar cerámicas que son vendidas en el zoco.

\section{Los procesos de cambio}

En un mundo cada vez más globalizado, la sociedad rifeña está también inmersa en un proceso acelerado de cambio. En lo que se refiere a la cerámica, hay factores que alteran el sistema 'tradicional' de producción. Los más evidentes son (1) la introducción de contenedores en otros materiales, sobre todo plásticos, (2) la monetarización de la economía que modifica sustancialmente los sistemas de intercambio y distribución y (3) la existencia de otros referentes sociales que limitan la transmisión de las artesanías al generar otras expectativas en la población rural. Esto tiene dos implicaciones. Por una parte clarifica que la observación no se aplica sobre un contexto prístino. Mas sucede que ninguno lo es y pretender lo contrario resultaría ilusorio e ingenuo. Y, por otra parte, esta situación permite acceder a algunos aspectos poco estudiados hasta ahora a partir de los registros etnoarqueológicos como son precisamente las adaptaciones que se producen en los comportamientos técnicos, económicos y sociales durante estos procesos de cambio.

Con la escasa perspectiva temporal que se consigue en un estudio etnoarqueológico, hemos percibido que se han producido cambios sustanciales en el conjunto del sistema de producción a lo largo de las últimas décadas y no sólo en los años más recientes. A menudo resulta difícil precisar la cronología de estos cambios 'históricos' que aquí transcribimos en ocasiones con una fórmula tibia: 'en el pasado...'. A pesar de la resistencia de las artesanas a reconocer la existencia de modificaciones, hemos apreciado cambios en los procesados, en los tipos y en las decoraciones de los recipientes fabricados, en el reparto de las tareas o en las formas de intercambio.

Es posible que los aspectos artesanales de esta producción se hayan potenciado a lo largo de este siglo, con la generalización de los zocos como puntos de comercialización (Picon, com. pers.). En el pasado, la producción para autoconsumo o intercambio en elduar debió ser más importante que lo que podemos observar en la actualidad. De hecho Fton, la ceramista más anciana que hemos entrevistado, de alrededor de 90 años, recuerda que, cuando ella era niña, la cerámica no se vendía en el zoco, sino que los compradores encargaban la producción en la casa de las ceramistas, además de practicarse la venta itinerante (para una evolución similar ver Dietler y Herbich, 1994a). A lo largo de este siglo ha habido un acceso cada vez mayor de la mujer al zoco, hecho que no era socialmente bien aceptado en el pasado.

¿Cuáles fueron las consecuencias del incremento de la importancia de los zocos como lugares de comercialización de la cerámica? Las investigaciones que hemos realizado hasta la fecha, basadas en los recuerdos de las ceramistas, apuntan algunas. $\mathrm{Al}$ introducir las cerámicas en un mercado que favorecía la competencia directa entre artesanas, la producción de cerámica decorada aumentó, ya que cada vez era más difícil vender las cerámicas no decoradas. La producción tendió a concentrarse en algunas aldeas, caracterizadas por la calidad de sus arcillas, como Briet, y/o la belleza de sus cerámicas decoradas, como Dahar y Ain Kob. A la vez, muchas ceramistas abandonaron la producción, especialmente las que vendían sus cerámicas a muy pequeña escala, en el propio duar.

En las aldeas donde la producción se mantuvo, la intensidad de fabricación se incrementó. Los mecanismos que permitieron esta intensificación de la producción apenas incluyeron innovaciones en el proceso, sino que se basaron en cambios en la organización del trabajo:

1. la concentración de la producción en manos de las ceramistas y las aldeas más especializadas,

2. el aumento del tiempo de dedicación,

3. la colaboración entre las ceramistas (Picon, com. pers.), como vimos en la mina de Ain Kob o en los hornos comunales, 
4. y la ayuda de los hombres para tareas poco especializadas y que requieren esfuerzo físico (recogida de leña).

Estos datos apuntan a que, ante la necesidad de afrontar una intensificación de la producción, se eligieron soluciones de ajustes en la estructura social del proceso productivo, antes que la adopción de innovaciones técnicas.

En otros ámbitos geográficos los cambios frente a estímulos de la misma naturaleza fueron más profundos. En Serbia se ha documentado una transformación más radical en la producción de la cerámica modelada hecha por mujeres, causada por el impacto del mercado. En una primera fase los hombres sustituyeron a las mujeres en la fabricación de la cerámica modelada, introduciendo posteriormente una innovación técnica: la torneta (Filipovic, 1951).

\section{CONCLUSIÓN}

La fabricación de cerámicas Gzaua representa un ejemplo de producción artesana con una escasa complejidad técnica, caracterizada por:

1. el trabajo individual, aunque con la posibilidad de desarrollar colectivamente algunas de las tareas,

2. con acceso libre a las materias primas, que se adquieren en ámbitos locales y por los propios artesanos,

3. realizado durante una temporada del año,

4. dedicando algunas horas al día, ya que las ceramistas ejectuan otros trabajos domésticos y productivos, como el resto de las mujeres no especialistas,

5. con técnicas sencillas, por urdido,

6. sin estructuras constructivas destinadas a la producción (taller, horno, almacén),

7. generando una producción escasa,

8. que, en su mayor parte, es vendida o intercambiada directamente por la artesana,

9. y distribuida en un área geográfica comarcal, restringida.

La reflexión etnoarqueológica que permiten estas observaciones se extiende a aspectos tan variados como el reconocimiento del procesado de cerámica, la función de los recipientes, la organización del trabajo, la posición social de los artesanos o los procesos de cambio.

a. Una parte de los procesos técnicos tiene una visibilidad arqueológica muy limitada. Esto es cier- to para la producción de cerámica a escala doméstica o para intercambio en el marco de la aldea, porque implica aprovisionamientos y tratamientos de la arcilla, tipos de instrumentos o estructuras de combustión que apenas dejan restos arqueológicos identificables. Sin embargo, la producción para el zoco acarrea (1) la incorporación de algunas estructuras novedosas, como son las minas o los hornos en cubeta, (2) el uso intenso de útiles específicos, como los cantos para el bruñido y (3) una preparación particular de la materia prima -con mezclas, molidos y cribados-, que proporcionan mejores evidencias.

b. Resulta evidente la vinculación entre varios aspectos de la función de los recipientes y otras variables como la forma, el acabado, la decoración, las formas de cocción o la composición de las arcillas. Las primeras resultan más contingentes o contextuales y por ello más difíciles de extrapolar para un estudio arqueológico pero las otras tienen que ver con las propiedades materiales de las piezas: resistencia al fuego o a los choques, impermeabilidad... Por ejemplo, hemos observado que las características de las arcillas empleadas en cada tipo de cerámica se relacionan directamente con su función. Esto llega al punto de que si diferentes partes del mismo recipiente cumplen funciones distintas se fabrican con mezclas de arcillas también diferentes -por ejemplo, las paredes que contienen líquidos frente a los cordones que reciben la decoración.

c. El sentido de las decoraciones y acabados ha sido examinado pero merece sin duda mayor atención en el futuro. Los acabados más cuidadosos de las superficies de las piezas mediante bruñido se explican por el uso que se da a estas piezas. Las decoraciones se organizan según ciertas reglas: (1) no se decoran las partes de los vasos que van a estar en contacto con el fuego; (2) en los recipientes de cocina se evita la decoración pintada, la que se realiza es más resistente, basada en cordones, apliques e impresiones; y (3) la decoración pintada se reserva para los contenedores de líquidos. Las ceramistas limitan el sentido de la decoración pintada, presentándola como un medio para mejorar la venta, al hacer más atractivas las cerámicas. Sin embargo, los contextos de uso de las cerámicas pintadas sugieren otras vías de explicación. Los recipientes pintados suelen emplearse en lugares públicos - para ir a la fuente o a la almazara, al recibir invitados-y tienen una carga evidente de representación social por parte del usuario. Se emplean también en contextos con fuertes contenidos simbólicos -la jarra en el

T. P., 58, n. ${ }^{\circ} 1,2001$ 
santuario o el barrada nupcial- por lo que no puede descartarse un sentido apotropaico.

d. El aprendizaje de las técnicas se produce de manera informal y sin restricciones en el marco familiar o vecinal. Hemos apreciado el mantenimiento de microtradiciones incluso locales, frecuentes en patrones de residencia uxorilocales, a pesar de que aquí el sistema es virilocal. Los mecanismos que preservan estas microtradiciones tienen que ver también con la transmisión de las técnicas. A menudo se produce un aprendizaje diferido en el que las mujeres comienzan la elaboración de la cerámica después del matrimonio y, por tanto, con las técnicas del duar de acogida.

e. La organización del trabajo es muy simple, con una escasa o nula división del trabajo, que solo aparece como respuesta a una intensificación de la producción. La observación de algunos casos nos ha permitido comprobar cómo responde el sistema de producción a esta necesidad de aumentar la producción. Algunos de los cambios tienen que ver con las técnicas de trabajo pero los más se relacionan con la organización social del trabajo. Los procesos técnicos se mantienen bastante estables; los aspectos más flexibles son los que se relacionan con la adquisición de la materia prima y con la cocción de los recipientes: aparecen las minas y los hornos, como hemos visto. No se producen cambios notables cualitativos sino cuantitativos. Los cambios en la organización del trabajo tienen sin embargo mayor entidad; éste parece ser el elemento que dota de una cierta flexibilidad al sistema de producción. Los mecanismos que se desarrollan implican una reorganización de las tareas a escala doméstica, local y regional. En el plano doméstico se produce una mayor dedicación en tiempo de las artesanas, la participación de las otras mujeres de la familia en la producción o la liberación de algunas tareas domésticas, y, en último término, la colaboración de los hombres. En el ámbito local aparecen los trabajos comunales sobre todo relacionados con los cambios técnicos descritos en las minas y en los hornos. A escala regional se genera una reorganización de los centros de producción; ésta se concentra en los lugares con mayor tradición cerámica que están a menudo vinculados a afloramientos de arcillas de calidad que les permiten producir recipientes pintados con mejores acabados y cualidades.

f. En este marco socio-económico la artesanía es una respuesta a la pobreza. La economía está basada en una agricultura y ganadería autosuficientes; los artesanos aparecen en las unidades domésticas que no disponen de suficientes tierras para producir los cereales, legumbres y frutas necesarios o para mantener los rebaños. El mercado está muy poco desarrollado por lo que los productos elaborados tienen un valor muy bajo en los intercambios y este valor queda establecido de forma casi discrecional por los compradores en relación con las fluctuaciones de las cosechas. En ocasiones, el encargo a los artesanos se concibe incluso como una forma de solidaridad. En consecuencia, las ceramistas tienen una posición social marginal, un rasgo que comparten con los demás especialistas artesanos de la región, tanto hombres como mujeres. Además de la división social existe también una división regional del trabajo, en el que las comarcas que no presentan condiciones para una economía agropecuaria suficiente desarrollan más, en términos comparativos, esta dedicación artesanal; ello resulta en una intensificación económica regional en el sentido de Shennan (1999).

g. El estudio de los fenómenos de cambio resulta especialmente difícil en la observación etnoarqueológica por su propia complejidad -debida a la interrelación de numerosos factores-, y por la escasa proyección temporal del trabajo de campo que obliga a recurrir a fuentes de información dispares -observación directa frente a encuesta o narración. El riesgo es que ello favorece una estrategia un tanto simplificadora en la que los cambios se deducen de una comparación entre un pasado evanescente - por lo mal documentado-forzado analíticamente a convertirse en un tiempo único ( $c f$. Caro Baroja, 1965) y un presente en el que la alteración de las formas de vida tradicionales es cada vez más acusada. Con todo, como describimos en los apartados a. y e. de esta conclusión, hemos percibido la mayor continuidad de los procesos técnicos, que mantienen similitudes en contextos y a escalas de trabajo muy diferentes, frente a la mayor flexibilidad y versatilidad de la organización social del trabajo que es la que suele servir para dar respuesta a las necesidades cambiantes.

\section{AGRADECIMIENTOS}

Agradecemos a Gabriel Camps, Carles Borràs i Querol, Jacques Vignet-Zunz, Biljana DjordjevicBogdanovic y Maurice Picon las informaciones y comentarios que han enriquecido este artículo. Hamid Essoufi ha participado con dedicación e inteligencia en las campañas de campo; además de él, 
otros compañeros y colegas han colaborado generosamente en las estancias en Marruecos y han aportado ideas sugerentes durante la redacción de este texto. La Fundación Marcelino Botín financia el proyecto de investigación que ha permitido la elaboración de este artículo. Recordamos con cariño a los hombres y mujeres marroquíes que nos han regalado con su hospitalidad. A todos ellos nuestro agradecimiento y amistad.

\section{BIBLIOGRAFÍA}

ARNOLD, D.E. (1985): Ceramic theory and cultural process. Cambridge University Press. Cambridge.

BAlfet, H. (1965): "Ethnographical observations in North Africa and archaeological interpretation: The pottery of the Mahgreb". En F.R. Marson (ed.): Ceramics and Man. Aldine. Chicago: 161-177.

BarAndiaRÁn, J.M. (1979): El hombre prehistórico en el País Vasco. Ediciones Vascas. San Sebastián ( $1^{a}$ edición, 1953).

- (1972-1983): Obras completas. La Gran Enciclopedia Vasca. Bilbao.

BEYRIES, S. (1997): "Systèmes techniques et stratégies alimentaires: l'exemple de deux groupes d'indiens de Colombie-Britannique". En L'alimentation des hommes du Paléolithique, E.R.A.U.L., 83. Université de Liège. Lieja: 73-92.

- (1999): "Etnoarchaeology: a method of experimentation”. En L.R. Owen y M. Porr (ed.): Ethno-analogy and the reconstruction of prehistoric artefact use and production. Mo Vince. Tubingen: 117-130.

Boulifa, A. (en prensa): “Contribution à l'étude de l'habitat traditionnel chez Beni Messauar (nord-ouest du Maroc)". En J.A. González Alcantud (ed.): Montañas mediterráneas. Universidad de Granada. Granada, 1999.

CAmps, G. (1987): Les Berbers. Mémoire et identité. Collection des Hesperides. Errance. París.

Caro Baroja, J. (1965): "Del folklore religioso europeo como disciplina histórica". Revista de Dialectología y Tradiciones Populares, 21 (3/4): 21-34.

Chiкhi, N.E. y El Abdellaoui, M. (1996): “El regadío y las transformaciones agrarias en el Rif'. En J.A. González Alcantud, M. González de Molina, A. Malpica y J. Vignet-Zunz (ed.): Transformaciones agrarias y cultura material en Andalucía oriental y norte de Marruecos. Diputación Provincial de Granada y Ministerio de Agricultura. Granada: 255-282.

Criado, F. (1993): "Límites y posibilidades de la Arqueología del Paisaje”. Spal, 2: 9-55.

Dietler, M. y Herbich, I. (1994a): "Ceramics and Ethnic Identity: Ethnoarchaeological observations on the distribution of pottery syles and the relationship between the social contexts of production and consumption". En
Terre cuite et société. La céramique, document technique, économique, culturel. XIV Rencontres Internationales d'Archéologie d'Antibes. APDCA. Juan-lesPins: 459-472.

- (1994b): 'L'Habitus et la reproduction sociale des techniques: l'intelligence du style en archéologie et ethnoarchéologie". En P. Latour y P. Lemonier (ed.): Techniques et lien social. La Découverte. Paris: 206-232.

FAYOLLE, V. (1992): La poterie modelée du Maghreb oriental. Laboratoire d'Anthropologie et de Préhistoire des Pays de la Mediteranée Occidentale. CNRS. París.

FERNÁNDEZ, V. (1994): "Etnoarqueología: una guía de métodos y aplicaciones". Revista de Dialectología y Tradiciones Populares, 49 (2): 137-169.

FILIPOVIC, M.S. (1951): Primitive ceramics made by women among the Balkan peoples. Monographs, 181 (2). Serbian Academy of Sciences. Belgrado: 157-170.

FOREST, J.-D. (1992): “L'archéologie et l'ethnologie ou la nécessité de 'mélanger les genres"'. En Ethnoarchéologie: justification, problèmes, limites. APDCA.Antibes: $25-32$

GALlAY, A. (1995): “L'ethnoarchéologie entre sciences et histoire. Une réflexion sur le développement des sciences de la nature". En A. Bazzana y M.C. Delaigue (pres.): Ethnoarchéologie méditerranéenne. Finalités, démarches et résultats. Casa de Velázquez. Madrid: $17-$ 27.

Gallay, A.; Huysecom, E.; Mayor, A. y Ceuninck, G. de (1996): Hier et aujourd'hui: des poteries et des femmes. Céramiques traditionnelles du Mali. Document du Département d'Anthropologie et d'Écologie, 22. Université de Genève, Ginebra

GÁNDARA, M. (1990): “La analogía etnográfica como heurística: lógica muestreal, dominios ontológicos e historicidad". EnY. Sugiura y M.C. Serra (ed.): Etnoarqueología. Coloquio Bosch-Gimpera. Universidad Nacional Autónoma de México. México: 43-82.

Gassin, B. (1996): Évolution socio-économique dans le Chaséen de la grotte de l'Église supérieur (Var). Monographie du CRA 17, CNRS. París.

Gelbert, A. (1999): "Technological and Stylistical Borrowing Between Ceramic Traditions: A Case study from Northeastern Senegal”. En L.R. Owen y M. Porr (ed.): Ethno-analogy and the reconstruction of prehistoric artefact use and production. MoVince. Tubingen: 207-224.

GonZÁlez URQuiJo, J.; IBÁÑEZ, J.J.;ZaPATA, L.; MoReno, M.; Peña-Chocarro, L.; Essouifi, H. y Gómez, E. (en prensa): "Technologies traditionnelles dans le Rif occidental". EnA. Zouggari: Le local: Espace de pratiques, de savoirs et de culture. I. V. Hassan II. Rabat.

Hernando, A. (1995): "La etnoarqueología, hoy: una vía eficaz de aproximación al pasado". Trabajos de Prehistoria, 52 (2): 15-30.

Hernando, A. (1997): “La identidad Q’eqchi. Percepción de la realidad y autoconciencia de un grupo de agricul-

T. P., 58, n. ${ }^{\circ} 1,2001$ 
tores de roza de Guatemala". Revista Española deAntropología Americana, 27: 199-220.

HODDER, I. (1977): "The distribution of material culture ite$\mathrm{ms}$ in the Baringo District, western Kenya". Man, 12: 239-269.

HoLE, F.D. (1978) Pastoral nomadism in western Iran. In: Gould, R.(ed.): Explorations in ethnoarchaeology. University of New Mexico Press.Albuquerque: 127-179.

IbÁÑEZ, J.J.; GONZÁLEZ, J.E.;ZAPATA, L.;PEÑA-ChOCARRo, L. y BEUGNIER,V. (en prensa, a): "Harvesting without sickles: Neolithic examples from humid mountains". En S. Beyries y P. Petrequin (ed.): Ethno-archaeology and its transfers. BritishArchaeological Report, International Series. 5th Meeting of the EAA, 1999. Bournemouth.

IbÁÑEZ, J.J.; PeÑa-ChoCARRo, L.; GonZÁlez, J.E. yZAPATA, L. (en prensa, $b$ ): "Les récipients en bouse de vache et argile non cuite (tabtoba et tonna) dans la région Jebâla (Maroc). Exemple d'un processus technique de type domestique". Techniques et Culture, 37.

IBÁÑEZ, J.J. y ZAPATA, L. (en prensa): "La función de los útiles de sílex del yacimiento de Pico Ramos". Isturitz, 11. Sociedad de Estudios Vascos.

KeELEY, L.H. (1992): "The use of plant foods among hunter-gatherers: a cross-cultural survey". En P. Anderson (ed.): Prehistoire de l'agriculture: nouvelles approches experimentales et ethnographiques. Monographies du C.R.A., 6. C.N.R.S. París: 29-38.

LONGACRE, W.A. (1981): "Kalinga pottery, an ethnoarchaeological study". En I. Hodder, G. Isaac y N. Hammond (ed.): Pattern of the past. Cambridge University Press. Cambridge: 49-66

PeCOCK, D.P.S. (1982): Pottery in the Roman world: An ethnoarchaeological approach. Longmans. Londres.

Peña-Chocarro, L.; Zapata, L.; González Urquijo, J. e IBÁÑEZ, J.J. (2000): “Agricultura, alimentación y uso del combustible: Aplicación de modelos etnográficos en arqueobotánica”. Saguntum, extra-3: 403-420.

Petrequin, P. y Petrequin, A.-M. (1992): “De l'espace actuel au temps archéologique ou les mithes d'un préhistorien". En: Ethnoarchéologie: justification, problèmes, limites: 211-238.APDCA, Antibes.

Picon, M (1993): "Pour une relecture de la céramique marocaine: characteristiques des argiles et des produits, techniques de fabrication, facteurs économiques et sociaux". En A. Bazzana y M.O. Delaigue (ed.): Ethnoarchéologie mediterranéenne. Finalités, démarches et résultats. Casa de Velázquez. Madrid: 141-158.

Porr, M. (1999): “Archaeology, analogy, material culture, society: an exploration. En L.R. Owen y M.Porr (ed.): Ethno-analogy and the reconstruction of prehistoric artefact use and production. Mo Vince. Tubingen: 315.

RENFREW, C. (1977): Production and exchange in early state societies: The evidence of pottery. En D.P.S. Peacock (ed.): Pottery and early commerce: Characterization and trade in Roman and later ceramics. Academic Press, Londres: 1-20.

REINA, R.E. y HiLl, R.M. (1978): The traditional pottery of Guatemala. University of Texas Press, Austin.

RICE, P.M. (1981): "Evolution of specialized pottery production: A trial model". Current Anthropology, 22 (3): 219-240.

- (1987): Pottery Analysis. A Sourcebook. The University of Chicago Press. Chicago.

RodRíGUEZ, A.C. (1999): "The reconstruction of ancient leather technology or how to mix methodological aproaches. An example from the Canary Island prehistory". En L.R. Owen y M. Porr (ed.): Ethno-analogy and the reconstruction of prehistoric artefact use and production. Mo Vince. Tubingen: 141-152.

STOcZKowsKI, W. (1992): Préhistoire, ethnologie et approche prédictive: la tentation d'une épistémologie spontanée. En Ethnoarchéologie: justification, problèmes, limites. APDCA, Antibes: 33-44.

Tilley, C. (1994): The phenomenology of lanscape. Places, paths and monuments. Berg. Oxford.

VAN DER LEeUw, S.E. (1984): Pottery manufacture: Some implications for the study of trade. En P.M. Rice (ed.) Pots and potters: Current approaches in ceramic archaeology. University of California Press: 55-69.

Vossen, R. (1990): Reisen zu Marokkos Töpfern. Forschungsreisen 1980 und 1987. Christians. Hamburgo.

Vossen, R. y EBert, W. (1986): Marokkanische Töpferei. Habelt, Bonn.

WallaerT-PÉTre, H. (1999): “Manual Laterality Apprenticeship as the First Learning Rule Prescribed to Potters". En L.R. Owen y M. Porr (ed.): Ethno-analogy and the reconstruction of prehistoric artefact use and production. Mo Vince. Tubingen: 185-206.

WYLIE, A. (1988): "'Simple' analogy and the role of relevance assumptions: implications of archaeological practice". International Studies in the Philosophy of Science, 2: 134-150.

WyLIE, M.A. (1985): “The reaction against analogy". En M.B. Schiffer (ed.): Advances in archaeologicalmethod and theory, 8.Academic Press. Nueva York: 63-111. 